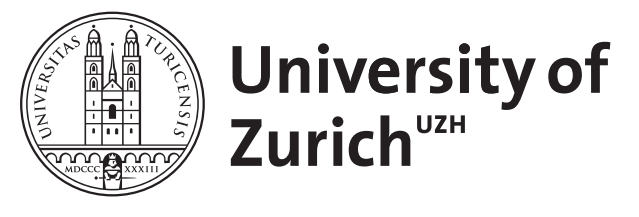

\title{
Mechanism and significance of chlorophyll breakdown
}

\author{
Christ, Bastien ; Hörtensteiner, Stefan
}

\begin{abstract}
Chlorophyll breakdown is the most obvious sign of leaf senescence and fruit ripening. A multistep pathway has been elucidated in recent years that can be divided into two major parts. In the first phase, which commonly is active in higher plants, chlorophyll is converted via several photoreactive intermediates to a primary colorless breakdown product within the chloroplast. The second part of chlorophyll breakdown takes place in the cytosol and the vacuole. During this phase, the primary colorless intermediate is modified in largely species-specific reactions to a number of similar, yet structurally different, linear tetrapyrrolic products that finally are stored within the vacuole of senescing cells. To date, most of the biochemical reactions of the first phase of chlorophyll breakdown have been elucidated and genes have been identified. By contrast, mechanisms of catabolite transport and modification during the second phase are largely unknown. This review summarizes the current knowledge on the biochemical reactions involved in chlorophyll breakdown, with a special focus on the second-phase reactions and the fate of by-products that are released from chlorophyll during its breakdown.
\end{abstract}

DOI: https://doi.org/10.1007/s00344-013-9392-y

Posted at the Zurich Open Repository and Archive, University of Zurich ZORA URL: https://doi.org/10.5167/uzh-104522

Journal Article

Accepted Version

Originally published at:

Christ, Bastien; Hörtensteiner, Stefan (2014). Mechanism and significance of chlorophyll breakdown. Journal of Plant Growth Regulation, 33(1):4-20.

DOI: https://doi.org/10.1007/s00344-013-9392-y 
Mechanism and Significance of Chlorophyll Breakdown

Bastien Christ ${ }^{1}$ and Stefan Hörtensteiner ${ }^{2}$

Institute of Plant Biology, University of Zurich, CH-8008 Zurich, Switzerland

${ }^{1}$ bastien.christ@botinst.uzh.ch

${ }^{2}$ Corresponding author, phone: +4144634 82 82, fax: +41 4463482 04, shorten@botinst.uzh.ch (1)

\section{ABSTRACT}

Chlorophyll breakdown is the most obvious sign of leaf senescence and fruit ripening. A multi-step pathway has been elucidated in recent years that can be divided into two major parts. In the first phase that is commonly active in higher plants chlorophyll is converted via several photoreactive intermediates to a primary colorless breakdown product within the chloroplast. The second part of chlorophyll breakdown takes place in the cytosol and the vacuole. During this phase, the primary colorless intermediate is modified in largely species-specific reactions to a number of similar, yet structurally different, linear tetrapyrrolic products that finally are stored within the vacuole of senescing cells. To date, most of the biochemical reactions of the first phase of chlorophyll breakdown have been elucidated and genes been identified. By contrast, mechanisms of catabolite transport and modification during the second phase are largely unknown. This review summarizes the current knowledge on the biochemical reactions involved in chlorophyll breakdown with a special focus on the phase two reactions and the fate of by-products that are released from chlorophyll during its breakdown.

\section{KEY WORDS}

chlorophyll breakdown, chlorophyll catabolites, detoxification, nutrient remobilization, senescence 


\section{A. INTRODUCTION}

Chlorophyll (Chl) breakdown is the hallmark of senescence because of its impact on the color of senescing organs: loss of green Chls unmasks yellow carotenoids and highlights the synthesis of red anthocyans. Why do plants degrade Chls? Chloroplasts have been shown to contain up to $75 \%$ of the nitrogen content in photosynthetic tissues (Peoples and Dalling 1988; Makino and Osmond 1991). Rubisco, the most abundant protein of the chloroplast, accounts for $20-30 \%$ of total leaf nitrogen and protein complexes of the thylakoids such as photosystems (PS) constitute the second largest pool of chloroplast nitrogen (Hörtensteiner and Feller 2002; Feller et al. 2008). During senescence and remobilization of chloroplast nutrients, Chls are uncoupled from Chl-binding proteins within the PS and become phototoxic. Therefore, coordinated Chl breakdown maintains cell viability during senescence and allows an efficient remobilization of nutrients to growing organs.

Most enzymes involved in $\mathrm{Chl}$ degradation are now characterized and form the so-called "PAO pathway" (Fig. 1). This pathway can be divided into two main parts. The first one occurs within the chloroplast at the thylakoid membrane and involves phototoxic catabolites. The second part of the PAO pathway consists of modifications of colorless $\mathrm{Chl}$ catabolites and their translocation from the chloroplast to the vacuole. Recently, new insights have been obtained on the topology of $\mathrm{Chl}$ degradation within the chloroplast as well as on cytosolic modifications of colorless catabolites. The aim of this review is to provide an updated summary of the PAO pathway and to discuss its biological functions.

\section{B. THE PAO PATHWAY}

\section{B.1 Detoxification of colored chlorophyll catabolites in the chloroplast}

\section{B.1.1 Conversion of $\mathrm{Chl} b$ to $a$}

Chl $b$ is converted to $\mathrm{Chl} a$ by the action of two enzymes, Chl $b$ REDUCTASE (CBR) and 7HYDROXYMETHYL Chl $a$ REDUCTASE (HCAR; Fig. 1; Tanaka and Tanaka 2011). Plants possess two isoforms of CBR called NON-YELLOW COLORING1 (NYC1) and NYC1-LIKE (NOL; Kusaba et al. 2007; Sato et al. 2009). In silico hydrophobicity analysis of NYC1 and NOL protein sequences predicted NYC1 to be a 
membrane protein and NOL to be a soluble protein (Kusaba et al. 2007). Furthermore, in vitro immunoprecipitation and localization experiments in rice (Oryza sativa) suggested that the two proteins could form heterodimers at the thylakoid membrane (Kusaba et al. 2007; Sato et al. 2009). Although only NOL activity has been demonstrated in vitro, the two enzymes are thought to catalyze the same reaction, i. e. the reduction of Chl $b$ to 7-hydroxymethyl $\mathrm{Chl} a(\mathrm{HMChl} a)$. Interestingly, an Arabidopsis (Arabidopsis thaliana) nycl nol double mutant does not show an altered $\mathrm{Chl} a / b$ ratio during the unstressed vegetative phase, but displays a staygreen phenotype during leaf senescence and seed maturation due to the retention of Chl $b$ (Horie et al. 2009). Taken together, these data suggest that NYC1 and NOL do not participate actively to Chl $a / b$ ratio regulation during the vegetative growth, but are required for developmental processes such as leaf senescence (Tanaka and Tanaka 2011). Finally, Chl $b$ to $a$ reduction appears to be crucial for light harvesting complex (LHC) degradation during senescence since nycl nol mutants retain particularly LHC proteins (Kusaba et al. 2007; Horie et al. 2009).

Recently, the enzyme catalyzing the second step of Chl $b$ to Chl $a$ reduction, conversion of HMChl $a$ to Chl $a$, was characterized in Arabidopsis (Meguro et al. 2011). HCAR contains a flavin adenine dinucleotide and an iron-sulfur center as cofactors, and phylogenetic analysis revealed that HCAR evolved from divinyl chlorophyllide reductase of the Chl biosynthesis pathway (Meguro et al. 2011). HCAR is able to catalyze the conversion of HMChl $a$ to Chl $a$ in vitro and T-DNA insertion mutants for HCAR accumulate low levels of HMChl $a$ during leaf senescence. Surprisingly, hcar mutants retain significant amounts of pheophorbide (Pheide) $a$, a downstream intermediate of the Chl degradation pathway. Pheide $a$ OXYGENASE (PAO, the enzyme catalyzing the degradation of Pheide; see below) protein levels were unchanged in hcar as compared to wild-type plants. These observations, together with the fact that Pheide $a$ accumulates in a hcar nycl nol triple mutant, suggest that HMChl or some degradation products of HMChl could inhibit PAO activity by an unknown mechanism, resulting in the accumulation of Pheide $a$ (Meguro et al. 2011).

There are strong evidences that the first step of $\mathrm{Chl} b$ degradation is its conversion to $\mathrm{Chl} a$. The main argument is that PAO is specific for the " $a$ " form of Pheide (Hörtensteiner et al. 1995; Pružinská et al. 2003). In addition, nycl nol mutants are unable to degrade Chl $b$ during leaf senescence. As mentioned above, nycl nol mutants retain large amounts of LHC protein indicating that $\mathrm{Chl} b$ to $a$ conversion is a prerequisite for both $\mathrm{LHC}$ and $\mathrm{Chl}$ $b$ degradation. Finally, it has been shown that $\mathrm{Chl} b$ to $a$ conversion must precede demetalation and 
dephytylation because HCAR is able to reduce HMChl $a$ in vitro but not 7-hydroxymethyl pheophytin $a$ or 7hydroxymethyl Pheide $a$ (Shimoda et al. 2012). All together, these data indicate that $\mathrm{Chl} b$ to $a$ conversion is necessary for $\mathrm{Chl} b$ and $\mathrm{Chl} b$-containing complex, i.e. LHC, degradation, and that $\mathrm{Chl} b$ to $a$ conversion (but not demetalation or dephytylation) is the first step of $\mathrm{Chl} b$ degradation. Thus, Chl $a$ degradation seems to be independent of $\mathrm{Chl} b$ to $a$ reduction. In line with this, Arabidopsis nycl nol degrades Chl $a$ and PS core complexes as wild-type (Horie et al. 2009). Furthermore, nycl cao double mutants of rice, in which the entire Chl cycle (interconverting $\mathrm{Chl} a$ and $\mathrm{Chl} b$ ) is abolished, solely produce $\mathrm{Chl} a$ during vegetative growth and are able to degrade it during leaf senescence (Kusaba et al. 2007).

Interestingly, it has been demonstrated that overproduction of $\mathrm{Chl} b$ in Arabidopsis leads to the incorporation of Chl $b$ into PS core complexes, which seems to partially inhibit their degradation during senescence (Hirashima et al. 2006; Sakuraba et al. 2010; Shimoda et al. 2012; Sakuraba et al. 2012a). These findings indicate that Chl $b$ to $a$ conversion has evolved specifically to act on LHC complexes. It is interesting to note that $\mathrm{Chl} b$ overproduction in Arabidopsis appears to also retard age-dependent senescence via transcriptional downregulation of senescence associated genes (SAG; Sakuraba et al. 2012a). Incorporation of Chl $b$ in PS core complexes, and their consequent increased stability, is thought to maintain active PS during the senescence phase. The increased photosynthetic capacity resulting from $\mathrm{Chl} b$ overproduction could modulate $S A G$ expression through an unknown signaling pathway (Sakuraba et al. 2012a).

\section{B.1.2 Destabilization of Chl-apoprotein complexes by STAY-GREEN}

Deletion of the chloroplast-localized protein STAY-GREEN (SGR), as the name implies, causes a stay-green phenotype (Hörtensteiner 2009). Conversely, many but not all mutations triggering a stay-green phenotype affect the SGR gene. Among more than 14 stay-green mutants identified in natural populations, mutagenesis screens or breeding programs of different plant species, eight are deficient of SGR (Hörtensteiner 2009; Schelbert et al. 2009). Notably, presence or absence of a functional SGR gene in pea (Pisum sativum) determines the color of the cotyledons (green or yellow), originally described by Mendel (Mendel 1866; Armstead et al. 2007). Furthermore, the commercial tomato (Solanum lycopersicum) variety "green-flesh" is also deficient in SGR (Barry et al. 2008). The brown coloration of ripe green-flesh fruits is due to Chl retention and simultaneous carotenoid accumulation. 
The exact role of the SGR protein, which does not contain any known domain, is still unclear (Hörtensteiner 2009). Suppression of $S G R$ leads to a cosmetic stay-green phenotype (Jiang et al. 2007; Park et al. 2007; Ren et al. 2007), i.e. photosynthesis capacity of $s g r$ mutants during leaf senescence decreases as in corresponding wildtypes. However, several LHC and core subunits of PSI and II are partially retained (Jiang et al. 2007; Park et al.

122 2007; Aubry et al. 2008). Together with the finding that SGR can interact with LHC proteins of PSII (Park et al. 2007), these observations suggest that SGR participates in the destabilization of Chl-apoprotein complexes of PSII during senescence. Recently, this hypothesis has been corroborated by the finding that SGR plays a central role in recruiting Chl catabolic enzymes (CCE) at the thylakoid membrane (Sakuraba et al. 2012b; Sakuraba et al. 2013).

Interestingly, SGR seems to also have other functions, not directly related to Chl degradation. SGR appears to be implicated in root nodule senescence (Zhou et al. 2011). Root nodules of legume species such as Medicago sativa and Medicago truncatula are specialized organs hosting soil bacteria capable of reducing atmospheric nitrogen to ammonium. Nodule senescence stops nitrogen fixation and results in the loss of the symbiotic interaction. Silencing of $S G R$ in $M$. truncatula was shown to affect nodule senescence, and thus indicates that SGR could also have a function in non-photosynthetic tissues (Zhou et al. 2011). Recently, SGR has been shown to regulate lycopene and $\beta$-carotene biosynthesis in tomato fruits (Luo et al. 2013). SGR directly interacts with PHYTOENE SYNTHASE 1, a carotenoid synthetic enzyme and thereby inhibits its activity. These two studies clearly demonstrate that SGR, besides its requirement for Chl breakdown, is also involved in other biochemical processes.

With regard to the recent knowledge acquired about dephytylation of Chl during leaf senescence (see below), it is likely that demetalation precedes dephytylation and thus occurs on Chl $a$ (Fig. 1; Morita et al. 2009; Schelbert et al. 2009; Ren et al. 2010; Shimoda et al. 2012). To date, the mechanism involved in Chl demetalation is unknown (Hörtensteiner 2012). Several biochemical approaches described the involvement of either a heatstable metal-chelating substance (MCS) or a metal-releasing protein (MRP; Vicentini et al. 1995; Shioi et al. 1996a; Suzuki and Shioi 2002; Büchert et al. 2011). All these studies used chlorophyllin (an artificial and soluble 
Chl derivative) as substrate, but not Chl (Hörtensteiner 2012). A recent proteomic study of plastoglobules in Arabidopsis annotated a possible MRP protein (Lundquist et al. 2012). However, analysis of T-DNA insertion lines in this gene did not show any delay in Chl degradation during dark-induced senescence (Luzia Guyer and Stefan Hörtensteiner, unpublished data). Release of $\mathrm{Mg}^{2+}$ from $\mathrm{Chl}$ is known to occur at slightly acidic $\mathrm{pH}$ (Saga and Tamiaki 2012). Thus, it can be speculated that the decrease of photosynthesis during senescence lowers the stromal $\mathrm{pH}$ sufficiently to remove $\mathrm{Mg}^{2+}$ from the $\mathrm{Chl}$ macrocycle. Thereby, SGR could have a decisive role; during vegetative growth, the stromal $\mathrm{pH}$ also decreases at night, but absence of senescence-regulated SGR, which is thought to destabilize Chl-apoprotein complexes (Park et al. 2007), could avoid massive demetalation of Chls before the onset of senescence. was able to cleave the phytol tail of Chls (Willstätter and Stoll 1911) thereby producing chlorophyllide. Later, Mayer et al. (1930) found CLH activity in several plant species and Holden (1961) partially purified CLHs from sugar beet (Beta vulgaris) and pea and further characterized their activity (Mayer 1930; Holden 1961). To date, more than 250 studies have been performed on plant CLHs according to the Web of Knowledge database (search performed with "chlorophyllase(s)" in titles). The majority of these studies describe the (partial) purification of CLHs from different plant species and the characterization of their in vitro activity. Cloning of CLH genes from plants such as Chenopodium album, Arabidopsis and citrus (Citrus sinensis) revealed that CLHs contain a lipase motif. In addition, gene transcription of most CLHs is highly induced by ethylene and JA treatments, which are known to promote senescence (Jakob-Wilk et al. 1999; Tsuchiya et al. 1999). However, two CLHs (Arabidopsis AtCLH2 and $C$. album $\mathrm{CaCLH}$ ) are not induced by phytohormones and show constitutively low levels of expression (Jakob-Wilk et al. 1999; Tsuchiya et al. 1999). Using biochemical and immunolocalization approaches, several studies could localize CLH to the chloroplast (Brandis et al. 1996; Matile et al. 1997; Harpaz-Saad et al. 2007; Azoulay-Shemer et al. 2011). In citrus, CLH appears to be post-translationally regulated by $\mathrm{N}$ - and $\mathrm{C}$-terminal proteolysis within chloroplast membranes and mature $\mathrm{CLH}$ was shown to be more active than the CLH precursor (Harpaz-Saad et al. 2007; Azoulay-Shemer et al. 2011). Collectively considered, all these data suggest a major role for CLH in hydrolyzing the phytol chain of Chl. However, reverse genetic approaches of CLH-deficient plants did not corroborate this hypothesis (Benedetti and Arruda 2002; 
Schenk et al. 2007). Although silencing of Arabidopsis AtCLH1 (Arabidopsis has two CLH homologues) was

178

believed to decrease chlorophyllide/Chl ratios in green leaves, analysis of T-DNA insertion mutant lines for AtCLH1 (clhl) and AtCLH2 (clh2) did not reveal any delay of Chl degradation during senescence in single as well as in double mutants (Benedetti and Arruda 2002; Schenk et al. 2007). Decrease and increase of chlorophyllide/Chl ratios caused by, respectively, silencing and overexpressing of CLH in Arabidopsis reported by Bendetti et al. (2002) could be experimental artefacts and may reflect the in vitro rather than the in vivo activity of CLH. Indeed, in this study, extraction of green pigments from plant tissue was performed in acetone at $4^{\circ} \mathrm{C}$ during $12 \mathrm{~h}$. However, $\mathrm{CLH}$ has been reported to be active in vitro under such conditions (Barrett and Jeffrey 1964). Lastly, the hypothesis that Arabidopsis CLHs are not involved in Chl degradation during agedependent and dark-induced leaf senescence is corroborated by the finding that AtCLHs are located in the cytosol of senescent cells (Schenk et al. 2007).

The question how the phytol group of Chl may be hydrolyzed during age-dependent leaf senescence remained unanswered until recently. Using an elegant in silico approach in Arabidopsis, Schelbert et al. (2009) could identify a chloroplast-targeted serine-type hydrolase, the mutation of which leads to a stay-green phenotype during leaf senescence (Schelbert et al. 2009). Surprisingly, this senescence-induced hydrolase is not active on Chl in vitro but was found to specifically hydrolyze the phytol chain of pheophytin (Phein) and to produce Pheide. The protein, termed Phein Pheide HYDROLASE (PPH), was shown to be indispensable for Chl degradation during leaf senescence in Arabidopsis and rice (Morita et al. 2009; Schelbert et al. 2009; Ren et al. 2010). Arabidopsis pph mutants are also affected in LHC and PS core subunit degradation, indicating that phytol cleavage, in addition to $\mathrm{Chl} b$ to $a$ reduction (see above), is crucial for degradation of PS proteins during leaf senescence (Schelbert et al. 2009).

\section{B.1.5 Opening and reduction of the macrocycle}

The light absorption capacity of tetrapyrroles and thus the potential phototoxicity of some Chl catabolites is mostly due to electron conjugation within the porphyrin ring (Hörtensteiner 2006; Scheer 2006; Hörtensteiner and Kräutler 2011). Opening of the macrocycle of Pheide $a$ by PAO and the subsequent reduction of the conjugated $\mathrm{C} 20 / \mathrm{C} 1$ double bond of the intermediate, red Chl catabolite (RCC), by RCC REDUCTASE (RCCR) are the two steps of the Chl degradation pathway that lead to the loss of Chl catabolite phototoxicity (Fig. 1; 
Hörtensteiner 2006; Hörtensteiner and Kräutler 2011). Thus, primary fluorescent Chl catabolite ( $p$ FCC), the product of the consecutive PAO and RCCR activities, is considered as non-phototoxic (Hörtensteiner 2006; Hörtensteiner and Kräutler 2011; Hörtensteiner 2012).

210

The enzymatic activities responsible for opening of the Pheide macrocycle and production of $p \mathrm{FCC}$ were originally detected in isolated intact gerontoplasts and were shown to be promoted by the supply of glucose-6phosphate or ATP (Schellenberg et al. 1990; Matile et al. 1992). Later, $p$ FCC production from Pheide was shown to be possible in vitro by using isolated thylakoid membranes and reduced ferredoxin (Schellenberg et al. 1993; Ginsburg et al. 1994). Partial purification of this activity from Brassica napus revealed its dependency on a stromal fraction, senescence inducibility and specificity towards Pheide $a$, i. e. Pheide $b$ not being a substrate (Hörtensteiner et al. 1995). Dependency of the activity on a stromal fraction was explained by the finding that the conversion of Pheide to $p \mathrm{FCC}$ was a two-step reaction performed by two enzymes, one localized in chloroplast membranes (PAO) and the other in the stroma (RCCR; Rodoni et al. 1997). For a long time, PAO was considered to localize to the chloroplast envelope but recent reconsideration of Chl catabolic enzyme localization revealed that PAO is rather inserted into the thylakoid membrane (Matile et al. 1996; Pružinská et al. 2003; Kleffmann et al. 2004; Sakuraba et al. 2012b). Further characterization of PAO has shown that the enzyme is a Fe-dependent monooxygenase belonging to the Rieske-type iron-sulfur oxygenase family (Hörtensteiner et al. 1998; Gray et al. 2002; Pružinská et al. 2003). Interestingly, an additional factor, called RCC FORMING FACTOR (RFF), indispensable for PAO/RCCR activity in vitro has also been described (Pružinská et al. 2005). RFF could be a reactive oxygen species (ROS)-scavenging protein such as a peroxidase possibly required to remove ROS that are likely produced as by-products of PAO activity (Silvain Aubry and Stefan Hörtensteiner, unpublished data).

Suppression of PAO in Arabidopsis, corn (Zea mays), rice and tomato has been shown to induce premature cell death (Spassieva and Hille 2002; Pružinská et al. 2003; Tanaka et al. 2003; Pružinská et al. 2005; Tang et al. 2011). Stay-green and cell-death phenotypes of Arabidopsis paol mutants (originally identified as accelerated cell death 1 (acd1; Greenberg and Ausubel 1993)) is due to the accumulation of Pheide $a$ (Pružinská et al. 2003; Tanaka et al. 2003). Surprisingly, the cell death phenotype of $P A O$ mutants is not strictly connected to light, but also occurs in the dark (Pružinská et al. 2003; Pružinská et al. 2005; Hirashima et al. 2009). Thus, rather than being solely phototoxic, Pheide has been speculated to act as signaling molecule that may be exported from the 
chloroplast, like suggested for Mg-protoporphyrin IX, the first intermediate of the Chl branch of the tetrapyrrole biosynthesis pathway (Mochizuki et al. 2001; Hirashima et al. 2009). However, characterization of METYHL ESTERASE (MES) 16, the enzyme demethylating FCCs in the cytosol of Arabidopsis (see below), revealed that an export of Pheide from the chloroplasts of paol is unlikely (Christ et al. 2012). In vitro, MES16 can demethylate Pheide and convert it to pyroPheide but pyroPheide was not detected in paol. However, when MES16 was mistargeted to the chloroplast, $75 \%$ of the Pheide accumulating in paol was converted to pyroPheide (Schelbert et al. 2009; Christ et al. 2012). This finding indicates that Pheide is most probably not a chloroplast-to-nucleus retrograde signal itself but rather seems to trigger a signaling cascade involving other factors.

RCCR has originally been cloned from barley (Hordeum vulgare) and Arabidopsis, and was localized to the chloroplast (Wüthrich et al. 2000). Reduction of RCC by RCCR occurs in a stereospecific fashion, which can be different between RCCR orthologues (Mühlecker et al. 1997; Mühlecker et al. 2000). For instance, Arabidopsis RCCR produces $p$ FCC whereas Capsicum annuum RCCR converts RCC into the $\mathrm{C} 1$-epimer of $p \mathrm{FCC}$, epi-pFCC (Hörtensteiner et al. 2000). Interestingly, the Arabidopsis RCCR stereospecificity can be manipulated by a Pheto-Val exchange at residue 218 (Pružinská et al. 2007). RCCR crystallisation and site-directed mutagenesis confirmed that residue 218 together with Glu154 and Asp291 are located within the substrate-binding pocket of RCCR and are required for its activity (Sugishima et al. 2009; Sugishima et al. 2010; Pattanayak et al. 2012). In contrast to senescence-related expression of $P A O$, Northern blot analysis revealed a constitutive expression of RCCR in leaves and roots (Wüthrich et al. 2000). Furthermore, RCCR was shown to be also targeted to the mitochondria, suggesting that RCCR could have other roles besides converting RCC to $p$ FCC (Mach et al. 2001). Loss of RCCR in Arabidopsis causes the acd2 phenotype, which is characterized by the spontaneous spreading of light-dependent cell death lesions during plant growth and development, and by constitutive activation of defenses in the absence of environmental stress (Mach et al. 2001; Yao and Greenberg 2006; Pružinská et al. 2007). acd2 accumulates RCC and RCC-like pigments in the vacuole, indicating that these tetrapyrroles can move within the cell (Pružinská et al. 2007). RCC and RCC-like pigments are thought to act as signaling molecules and trigger the cell death observed in acd2 (Mach et al. 2001; Yao and Greenberg 2006; Pattanayak et al. 2012). Part of the cascade leading to cell death in $\operatorname{acd} 2$ is the loss of the mitochondrial membrane potential and mitochondrial $\mathrm{H}_{2} \mathrm{O}_{2}$ production (Yao and Greenberg 2006). Specific targeting of RCCR to the mitochondria of $a c d 2$ dramatically reduces RCC accumulation, cell death and mitochondrial ROS 
production (Pattanayak et al. 2012). This rescue effect is dependent on the activity of RCCR since a mitochondria-targeted Glu154Ala variant of RCCR did not complement the cell death phenotype of acd2. Collectively, these in vivo data on RCCR function(s) provide evidence that this enzyme is involved in protection against pro-death molecules (such as RCC) in both chloroplast and mitochondria. These pro-death molecules, substrates of RCCR, are mobile within cells and have a major effect on mitochondria (Pattanayak et al. 2012).

Recently, advances have been made in understanding the topology of the first steps of Chl breakdown during leaf senescence (Sakuraba et al. 2012b; Sakuraba et al. 2013). Using co-immunoprecipitation and bimolecular fluorescence complementation approaches, it has been demonstrated that SGR, NYC1, NOL, HCAR, PPH, PAO and RCCR interact at the thylakoid membrane (Fig. 2). These interactions are proposed to create an enzyme complex, which mediates channelling of phototoxic catabolites. The observation that these interactions do not occur in a sgr mutant suggests the possibility that SGR recruits the other CCEs at the thylakoid membrane and acts as a hub. In the model proposed by Sakuraba et al. (2012b), all these steps of Chl degradation occur at the thylakoid membrane and ultimately lead to the release of $p \mathrm{FCC}$, the first non-phototoxic catabolite, into the stroma. SGR has been shown to specifically interact with LHCII but not with LHCI subunits, and to participate in the destabilization of the Chl-apoprotein complexes (Park et al. 2007). Existence of the same or a similar complex for Chl degradation in PSI is highly probable but has not yet been demonstrated.

After its release into the chloroplast stroma, non-phototoxic and colorless $p$ FCC is modified by different enzymes, leading to the production of modified FCCs ( $m$ FCCs). All colorless Chl catabolites are thought to derive from $p \mathrm{FCC}$, to be modified in both chloroplast and cytosol, and finally to be non-enzymatically isomerized and stored in the vacuole as nonfluorescent Chl catabolites (NCCs) or dioxobilin-type nonfluorescent Chl catabolites (DNCCs). Since the identification of the first NCC, Hv-NCC-1 in 1991 (Kräutler et al. 1991), up to 40 different colorless Chl catabolites have been structurally characterized (Table 1; Hörtensteiner 2012). 
These catabolites are divided into four classes (FCCs, NCCs, DNCCs and YCCs; Fig. 1) depending on specific modifications at several side positions of the tetrapyrrole backbone, which determine a distinct UV/Vis spectrum for each class of catabolites (Fig. 3). The recently identified yellow Chl catabolites (YCCs) have been speculated to originate from the oxidation of NCCs in the vacuole (Moser et al. 2008a; Scherl et al. 2012).

\section{B.2.2 Demethylation}

Demethylation of $\mathrm{Chl}$ catabolites at $\mathrm{C} 13^{2}$ is species-specific: demethylated $\mathrm{Chl}$ catabolites have so far only been found in Arabidopsis, rape (Brassica napus) and spinach (Spinacia oleracea; Mühlecker and Kräutler 1996; Berghold et al. 2002; Pružinská et al. 2005; Hörtensteiner and Kräutler 2011). In a recent study, Arabidopsis MES16 was identified as the enzyme catalyzing demethylation of Chl catabolites (Christ et al. 2012). MES16 localizes to the cytosol and in vivo acts within the Chl degradation pathway on the level on FCCs but not on Pheide, like suggested in previous studies that proposed pheophorbidase, a homolog of MES16, to demethylate Pheide to pyroPheide in Chenopodium album and radish (Raphanus sativus; Shioi et al. 1996b; Suzuki et al. 2002; Suzuki et al. 2006). Notably, demethylation of FCCs accelerates their isomerization in the vacuole. As a consequence, senescent leaves of Arabidopsis mes 16 mutants are fluorescent under UV light due to the vacuolar accumulation of methylated FCCs. Interestingly, mes 16 mutants are not affected in Chl $a$ and $b$ degradation and do not show any visible phenotype under controlled growth conditions.

\section{B.2.3 Hydroxylation and glucosylation}

$\mathrm{C} 8^{2}$ hydroxylation of $p \mathrm{FCC}$ is the only side chain modification found in all species from which colorless Chl catabolites have been structurally characterized. The nature of the enzyme(s) responsible for hydroxylation is not known. However, isolation of gerontoplasts from barley revealed that not only $p \mathrm{FCC}$ is produced in organello but also a second, more polar, FCC (Matile et al. 1992). The structure of this polar FCC has not yet been determined, but was speculated to be $\mathrm{C} 8^{2}$ hydroxy- $p \mathrm{FCC}$ and cytochromes $\mathrm{P} 450$ monooxygenases have been suggested as possible candidates for $p \mathrm{FCC}$ hydroxylation (Matile et al. 1999). Although the majority of the 244 full-length P450 proteins that are encoded in the Arabidopsis genome are predicted to localize in the ER, some P450 have been experimentally shown to be targeted to the chloroplast (Schuler et al. 2006). However, darkincubation of detached Arabidopsis leaves in an atmosphere containing carbon monoxide (CO), known to be an 
inhibitor of cytochrome P450s, does not seem to prevent FCC hydroxylation (Christ et al. 2013). Assuming that CO can diffuse into the chloroplast, FCC hydroxylation thus appears not to be mediated by a cytochrome $\mathrm{P} 450$ enzyme.

In some species such as Arabidopsis, tobacco (Nicotiana rustica) and rape, the $\mathrm{C} 8^{2}$ hydroxyl group of FCCs appears to be subsequently malonylated and/or glucosylated (Hörtensteiner 1998; Berghold et al. 2004; Pružinská et al. 2005). The molecular nature of respective activities remains unknown, although a malonyltransferase activity has been partially purified from Brassica napus (Hörtensteiner, 1998). Arabidopsis UDP-DEPENDENT GLYCOSYLTRANSFERASES (UGTs) are known to catalyze the addition of a sugar group to hydroxyl groups of target molecules by formation of a glycosidic bond (Paquette et al. 2003; Osmani et al. 2009). Therefore, it can be imagined that one or several of the 120 cytosol-localized UGTs (Paquette et al. 2003) are responsible for the addition of glucose to $\mathrm{C} 8^{2}$ hydroxy-FCCs in Arabidopsis.

\section{B.2.4 Deformylation}

Deformylated Chl catabolites have been found in barley, Norway maple (Acer platanoides) and Arabidopsis, and are known as DNCCs (Losey and Engel 2001; Müller et al. 2011; Christ et al. 2013). NCCs and DNCCs differ at the C6 side group of pyrrole ring B, which is a formyl group in NCCs and an oxo group in DNCCs. DNCCs are the major Chl catabolites in Arabidopsis, accounting for more than $80 \%$ of all final Chl catabolites (Christ et al. 2013). Cytochrome P450 (CYP) CYP89A9 has recently been identified in Arabidopsis to be responsible for the oxidative deformylation of FCCs to dioxobilin-type FCCs (DFCCs), extending the wide substrate spectrum of CYPs (Bak et al. 2011) to linear tetrapyrroles. cyp89a9 mutants do not produce DNCCs but accumulate proportionally higher amounts of NCCs. CYP89A9, as most CYP proteins, likely localizes to the ER membrane. Interestingly, deformylation of FCCs by CYP89A9 must precede demethylation by MES16 since demethylated catabolites are not substrates of CYP89A9, suggesting a close interaction between the ER and the chloroplast envelope (Fig. 2).

\section{B.2.5 Hypermodification}



groups such as digalactosylglycerol or daucic acid (Moser et al. 2008b; Moser et al. 2009; Banala et al. 2010; Kräutler et al. 2010; Vergeiner et al. 2013). $h m$ FCCs were shown to be persistant and to accumulate in senescent leaves, because the $\mathrm{C} 17$ modifications inhibit their isomerization to respective NCCs (Moser et al. 2009; Vergeiner et al. 2013). Although it remains to be experimentally proven, $h m$ FCCs are, like most $m$ FCCs, most probably also imported into the vacuole. As a consequence of the accumulation of $h m \mathrm{FCCs}$, ripe fruits and senescent leaves of some species such as banana (Musa acuminate or Musa cavendish) and Spathiphyllum wallisii are fluorescing under UV light. Interestingly, in a yellow banana fruit, more intense fluorescence than in other parts of the peel is observed around necrotic spots that first appear around stomata (Moser et al. 2009). Occurence of these highly fluorescent rings is thought to result from the conversion of $m \mathrm{FCCs}$ to specific $h m \mathrm{FCCs}$ just prior to cell death. The mechanism increasing fluorescence in the surrounding of the necrotic spots remains unknown. De novo $h m$ FCCs synthesis from Chl precursors is unlikely. However, it could be due to the degradation of remaining $\mathrm{Chl}$ in the yellow peel of banana, although most $\mathrm{Chl}$ has already been broken down at this stage.

$m$ FCCs have been described to be converted to their respective NCCs inside the vacuole by nonenzymatic isomerization. This significantly occurs only under acidic conditions such as found in the vacuole (pH 5-6; Fig. 1 and 2; Oberhuber et al. 2003). Likewise, DFCCs produced by CYP89A9 in Arabidopsis through an oxidative deformylation of FCCs, were also shown to be converted to respective DNCCs at pH 5 in vitro (Christ et al. 2013). The rate of FCC-to-NCC isomerization increases with decreasing $\mathrm{pH}$ and seems to be also influenced by certain modifications of FCC side chains (Moser et al. 2009; Christ et al. 2012). Thus, $m$ FCCs harbouring an intact methyl group at $\mathrm{C} 13^{2}$ show slower isomerization in vitro when compared to demethylated FCCs (Christ et al. 2012). Moreover, $\mathrm{C} 17^{3}$ modifications found in $h m F C C \mathrm{~s}$ are thought to inhibit their conversion to $h m \mathrm{NCCs}$ (Moser et al. 2009). 
Chl degradation starts in the chloroplast and ends in the vacuole (Fig. 2). Therefore, two translocation systems have to transport $\mathrm{Chl}$ catabolites across the chloroplast envelope and the tonoplast. A single study on $\mathrm{Chl}$ catabolite transport across the plastid envelope showed that the release of FCCs from isolated barley gerontoplasts is enhanced by external supply of ATP (Matile et al. 1992). This observation has led to the hypothesis that transport of FCCs across the chloroplast envelope could be mediated by ATP BINDING CASSETTE (ABC) transporter(s) (Hörtensteiner 2006). Interestingly, suppression of ABCG2, a mammalian ABC-type transporter of the G subfamily, in mice triggers a porphyria-like phenotype (phototoxic ear lesions), which is due to the incapacity of the animals to detoxify food-derived Pheide and protoporphyrin IX circulating in the blood stream (Jonker et al. 2002). The Arabidopsis genome encodes 130 ABC transporters, which are localized in membranes of most subcellular compartments (Kang et al. 2011a). To date, screening single and multiple T-DNA insertion lines for $\mathrm{ABCG} 2$ homologues and other $\mathrm{ABC}$-transporters that are predicted to localize to the chloroplast envelope did not provide any evidence for their involvement in FCC export from the chloroplast (Sylvain Aubry, Bastien Christ, Silvia Schelbert, Maja Schellenberg, Kathrin Salinger and Stefan Hörtensteiner, unpublished data). Most probably, chloroplast export of FCCs and likely also of other linear tetrapyrrole such as phytochromobillin is performed by several transporters. This potential redundancy increases the difficulty of identifying these transporters in vivo.

401

Compared to the transport across the chloroplast envelope, import of FCCs from the cytosol to the vacuole is better understood. Heterologous expression in yeast of Arabidopsis AtABCC2 and AtABCC3, two members of the C subfamily of ABC transporters, revealed them to be capable of importing NCCs in vitro (Lu et al. 1998; Tommasini et al. 1998). Although these results have been obtained using NCCs rather than FCCs as substrate, this type of transporters is most probably involved in Chl catabolite transport across the tonoplast in vivo. However, like for the export of FCCs from the chloroplast, redundancy could render their reverse genetic identification difficult. B.2.8 Storage of tetrapyrrole catabolites or further degradation?

Monopyrrolic catabolites of $\mathrm{Chl}$ have been shown to accumulate during leaf senescence in barley and radish (Suzuki et al. 1999; Suzuki and Shioi 1999). This finding is consistent with the observation that DNCCs and 
has been degraded (Kräutler et al. 1991; Losey and Engel 2001; Aditi Das and Stefan Hörtensteiner, unpublished data). By contrast, in Arabidopsis, quantification of DNCCs and NCCs accumulating in yellow leaves revealed that their amount reflects the Chl content of green leaves, indicating that DNCCs and NCCs are not further fragmented (Christ et al. 2013). The same observation was made in Cercidiphyllum japonicum (Curty and Engel 1996). Together, these studies imply that the fate of NCCs/DNCCs in the vacuole (storage or further fragmentation) differs between plant species. However, it cannot be excluded that the inconsistency between amounts of colorless catabolites and degraded $\mathrm{Chl}$ in some species is due to a second and entirely different pathway for Chl breakdown that may be independent of PAO activity.

During leaf senescence, one mole of degraded Chl leads to the production of one mole of colorless catabolites.

Within the chloroplast this leads to the release of magnesium and phytol as by-products (Fig. 1). Magnesium is thought to be reallocated to growing tissues together with other metal ions set free during the degradation of thylakoid components. Two main routes have been described for the fate of phytol. Free phytol can be phosphorylated to phytoldiphosphate through the sequential action of two kinases and is subsequently employed for tocopherol synthesis (Valentin et al. 2006; Ischebeck et al. 2006). Recently, characterization of the two acyltransferases PHYTYL ESTER SYNTHASE 1 and 2 provided evidence for an alternative destiny of free phytol, i.e. through fatty acid phytyl ester (FAPE) synthesis in plastoglobules (Lippold et al. 2012).

FCC modifications also lead to the formation of by-products. Even though it has not been experimentally shown, Chl catabolite demethylation (through MES16) and oxidative deformylation (through CYP89A9) are thought to produce methanol and formate, respectively (Fig. 1). In Arabidopsis, the amount of Chl catabolites produced during leaf senescence is about $1 \mu \mathrm{mol}$ per gram fresh weight. Under the assumption that $100 \%$ of the $\mathrm{Chl}$ catabolites are demethylated and deformylated, Chl breakdown is responsible for the formation of $1 \mu$ mol each of methanol and formate per gram fresh weight, amounts that are not negligible. Methanol is known to be produced in leaves by processes such as pectin and lignin degradation and to be metabolized by C1-metabolism via production of formate or to exit the leaf via the stomata (Fall and Benson 1996; Igamberdiev et al. 1999; Gout et al. 2000). Although stomata are thought to remain open during the late stages of senescence (Zhang and Gan 2012), it can still be imagined that Chl-derived methanol may partially accumulate within the leaves and 
have physiological effects. Indeed, in rice, methanol formation during leaf senescence has been connected to an increase in tryptophan biosynthesis that involves the transcription factor WRKY14 (Kang et al. 2011b). Tryptophan biosynthesis has been shown to promote serotonin production, which in turn delays leaf senescence (Kang et al. 2009). Furthermore, exogenous application of methanol modulates the expression of hundreds of genes involved in multiple detoxification and signaling pathways (Downie et al. 2004). Although a regulatory role of methanol during senescence in Arabidopsis has not been established, it may be interesting to investigate the contribution of $\mathrm{Chl}$ catabolite demethylation to the total production of methanol during leaf senescence. However, the possibility that FCC demethylation may indirectly regulate gene expression is rather unlikely, because mes 16 mutants do not show any accelerated or delayed leaf senescence phenotype.

In leaves, formate is known to be the by-product of photorespiration and fermentation pathways, and possibly the product of direct $\mathrm{CO}_{2}$ reduction in chloroplasts (Igamberdiev et al. 1999). As mentioned above, formate could also be formed from methanol generated by pectin and lignin degradation, and potentially also by FCC demethylation. In theory, FCC-to-DFCC conversion by CYP89A9 should also contribute to the formation of formate in senescent leaves. Because formate is less volatile than methanol, it has to be metabolized within senescing leaves. Two routes for formate utilization have been described in plants (Igamberdiev et al. 1999). The first one is mediated by FORMATE DEHYDROGENASE (FDH) which converts formate to $\mathrm{CO}_{2}$ (Li et al. 2000; Olson et al. 2000). Although overexpression of FDH in Arabidopsis has been shown to increase tolerance to exogenous application of formate, the role of FDH in leaves remains unknown ( $\mathrm{Li}$ et al. 2002). Transcriptome coexpression analysis using ATTED-II (Obayashi et al. 2009) reveals that Arabidopsis FDH is co-expressed with CCEs, indicating that the enzyme could have a role during leaf senescence. To the best of our knowledge, accumulation of formate in $f d h$ mutants has never been reported in the literature. Furthermore, Arabidopsis fdh mutants do not show any accumulation of formate during dark-induced leaf senescence (Bastien Christ and Stefan Hörtensteiner, unpublished data). The non-accumulation of formate in $f d h$ mutants could arise from a compensation effect of a second route of formate utilization. Indeed, formate can be condensed with tetrahydrofolate (THF) to produce formyl-THF by the action of 10-FORMYL-THF SYNTHETASE (THFS; Igamberdiev et al. 1999). Formyl-THF is then further used for serine and methionine biosynthesis. In Arabidopsis, THFS is encoded by a single copy gene but has not been analyzed so far. 


\section{SIGNIFICANCE OF CHLOROPHYLL BREAKDOWN}

476

\section{C.1 Detoxification and nutrient remobilization}

After the onset of senescence, leaves undergo complex changes that should be seen as "transdifferentiation" rather than as "deterioration" processes (Thomas et al., 2003). Recycling and detoxification of (macro-) molecules are indeed the consequences of structural and biochemical changes occurring during leaf senescence. Disintegration of cellular components is mediated through fine-tuned catabolic as well as anabolic steps that reduce deleterious effects of intermediates of degradation and maximize nutrient remobilization (e.g. nitrogen, phosphorus, sulphur, minerals, metals ions and carbon skeletons). Chl breakdown is a direct prerequisite for the remobilization of chloroplast lipids, proteins and metals. This fact is highlighted by the effect of the suppression of enzymes involved in Chl breakdown such as PAO or RCCR (see above), which lead to the accumulation of toxic Chl intermediates and, thus, to early cell death phenotypes. Although it has not yet been precisely characterized, these mutants seem to be also affected in the ability to remobilize nutrients and consequently show a low germination rate. In addition, it has been demonstrated in Arabidopsis that the suppression of Chl $b$ to $a$ conversion, which leads to Chl retention in cotyledons during seed drying, dramatically decreases seed germination capacity (Nakajima et al. 2012).

\section{C.2 Protection against pathogens}

Several lines of evidence suggest that (partial) degradation of Chl is involved in the response of plants against pathogens. SGR appears to be necessary for the development of chlorosis upon infection of Arabidopsis with Pseudomonas syringae pv tomato (Mecey et al. 2011). Similarly, levels of SGR in silencing or overexpressing Arabidopsis lines correlate with the severeness of the hypersensitive response triggered upon $P$. syringae infection (Mur et al. 2010). Moreover, AtCLH1 was proposed to be involved in pathogen responses (Kariola et al. 2005). Silencing of AtCLH1 was shown to alter resistance or susceptibility of plants towards two different types of necrotrophic pathogens, Erwinia carotovora and Alternaria brassicicola. Absence of CLH1, which is thought to degrade $\mathrm{Chl}$ in damaged tissue, was connected with ROS production during necrotrophic pathogen attack, which in turn would activate and inactivate salicylic acid-dependent and jasmonic acid-dependent responses, respectively (Kariola et al. 2005). However, this model for CLH function during pathogen attack is 
based on indirect observations and has to be considered with caution. Together, these studies suggest that Chl breakdown enzymes and catabolites could play an important role during pathogen infection.

\section{C.3 Putative role(s) of FCC modifications}

Retention of FCCs in mes16 mutants and lack of DNCC formation in cyp89a9 mutants does not seem to affect plant growth and/or leaf senescence, i.e. no phenotype was observed in mes16, cyp89a9 and mes16 cyp89a9 mutants during vegetative growth, and $\mathrm{Chl} a$ and $b$ degradation during leaf senescence was indistinguishable from wild-type plants (Christ et al. 2012; Christ et al. 2013). Thus, the role(s) of FCC modification remain(s) unclear. One hypothesis is that FCC modification could participate in the detoxification of Chl catabolites. The first steps of degradation produce phototoxic catabolites and FCC modifications could lead to further decrease of the light absorption capacities of the catabolites (Fig. 4). Indeed, demethylation of FCCs increases the rate of isomerization to nonfluorescent catabolites and, thus, facilitates the loss of their $360 \mathrm{~nm}$ absorption peak. Furthermore, DFCC formation by CYP89A9 results in the loss of the C5-formyl group of FCCs and, consequently, of the $320 \mathrm{~nm}$ absorption peak. One reason for the absence of any phenotype in mes 16 and cyp89a9 mutants could be the fact that in controlled experimental facilities these mutants are grown under UVlimited conditions. It can be speculated that, during senescence under sun-light conditions, plants could be affected if colorless $\mathrm{Chl}$ catabolites are retained that absorb light between 300 and $380 \mathrm{~nm}$. This hypothesis could be tested by growing the mutants under natural or artificial UV-B-containing light conditions.

Besides reducing the light absorption capacity of colorless Chl catabolites, modifications of FCC side chains increase their polarity (Fig. 1). This observation corroborates the idea that FCC modification directly contributes to Chl catabolite detoxification. Indeed, sequential hydroxylation and glucosylation steps are known to participate in the detoxification of various molecules such as xenobiotics by increasing their polarity (Pedras et al. 2001; Dosnon-Olette et al. 2011). Therefore, an increase in the solubility of the catabolites likely facilitates the relocation of FCCs from the chloroplast to the vacuole. Identification of the enzyme(s) responsible for FCC hydroxylation, together with the knowledge on FCC demethylation and oxidative deformylation could help testing if FCC modification has indeed a physiological role. It would be of interest to study leaf senescence in Arabidopsis plants that are deficient in all FCC modifying activities and would thus accumulate only $p \mathrm{FCC}$ and $p$ NCC during Chl breakdown. 
Why do FCC modifications occur in a species-specific manner (see Table 1)? One hypothesis is that FCCs could have ecological functions. On one hand, plants such as Arabidopsis appear to avoid FCC accumulation. On the other hand, permanent FCC accumulation has been shown to occur in leaves and fruits of banana and other related taxa (Moser et al. 2009; Kräutler et al. 2010; Hörtensteiner and Kräutler 2011; Vergeiner et al. 2013). Furthermore, while humans are not overly sensitive to blue light between 400-500 nm, other animals, such as insects, are known to possess blue photoreceptors having a maximal sensitivity around $450 \mathrm{~nm}$ (Briscoe and Chittka 2001). It is therefore reasonable to assume that some insects are able to detect the blue fluorescence emitted by FCCs around $450 \mathrm{~nm}$. In the case of plant species such as banana that naturally retain FCCs these fluorescent catabolites may play a role in beneficial interactions with insects such as pollinations or may be a signal of fruit ripening for bigger animals contributing to seed dispersal. Other plant species may benefit from the further conversion of FCCs into NCCs/DNCCs because herbivores might be able to link FCC fluorescence of senescent leaves with reduced plant fitness at this late developmental stage. Thus, by facilitating FCC-to-NCC isomerization, MES16 could, for instance, help avoiding the attraction of herbivores by the plant during nutrient relocation and seed maturation. Arabidopsis mutants that accumulate different relative FCC amounts during senescence (mes16, mes16 cyp89a9; Christ et al. 2012; Christ et al. 2013) could be used in future experiments to investigate if insects can indeed detect FCC fluorescence.

\section{FUTURE PERSPECTIVES}

554

Delaying the onset of leaf senescence has been described as a good strategy for increasing crop productivity (Thomas and Howarth 2000). Indeed, the yield record in corn was obtained with functional stay-green mutants. Though, suppression of Chl degradation only leads to cosmetic stay-green and/or cell-death phenotypes, which do not increase plant fitness but rather accelerate cell death and decrease seed germination. Nonetheless, understanding Chl breakdown during leaf senescence, fruit ripening and other developmental processes or stress responses is not only of interest to increase our fundamental knowledge, but it can also improve post-harvest storage. Indeed, loss of the green color due to senescence in vegetables such as broccoli (Brassica oleracea) decreases their commercial value. Besides open questions about FCC modifications and transport, several other aspects of $\mathrm{Chl}$ breakdown by the PAO pathway need further investigation. For instance, although SGR and 
Chl-apoprotein complexes during senescence, its mechanism of action remains to be defined. Furthermore, it is unknown if the same mechanism is involved in the degradation of Chl from PSI. It cannot be excluded that PSI degradation (partially) differs from the one of PSII. Recent studies, showing that SGR has other functions besides Chl breakdown could be helpful to better understand the role(s) of this protein. The mechanism involved in Chl demetalation also remains unknown. Whether it involves an MRP, MCS and/or simple changes in the $\mathrm{pH}$ of the chloroplast stroma still needs to be demonstrated. The in vivo role of CLHs, proteins that are highly active on Chl in vitro, is still unclear. A collective consideration of key studies on CLHs points to their involvement during stress responses against various biotic and abiotic stresses, and not during age-dependent leaf senescence.

Chl degradation is a highly controlled process. This is seen by protein-protein interactions during the first steps of the pathway that allow metabolic channelling of phototoxic catabolites (Sakuraba et al. 2012b; Sakuraba et al. 2013) and by the high co-regulation of Chl catabolic gene expression. However, the mechanism(s) of transcriptional regulation of $\mathrm{Chl}$ breakdown remain(s) unknown. Interestingly, overexpression of a single $\mathrm{CCE}$ results in an increased rate of degradation in the whole pathway (Sakuraba et al. 2012b). Finally, another very interesting research area in Chl breakdown is to better understand how cell death is triggered by the accumulation of Chl catabolites in mutant such as acdl and acd2. Interestingly, cell death in neither mutant is mediated through a singlet oxygen signaling pathway involving EXECUTER proteins (Wagner et al. 2004) and therefore seems to involve different, unknown mechanisms (Pattanayak et al. 2012; Stefan Hörtensteiner, unpublished data).

\section{ACKNOWLEDGEMENTS}

This work on chlorophyll breakdown was financially supported by grants from the Swiss National Science Foundation, the National Center of Competence in Research Plant Survival, a research program of the Swiss National Science Foundation, and CropLife, an European FP7 Marie-Curie Initial Training Network project. 
Armstead I, Donnison I, Aubry S, et al. (2007) Cross-species identification of Mendel's I locus. Science 315:73.

Aubry S, Mani J, Hörtensteiner S (2008) Stay-green protein, defective in Mendel's green cotyledon mutant, acts independent and upstream of pheophorbide $a$ oxygenase in the chlorophyll catabolic pathway. Plant Mol Biol 67:243-256.

Azoulay-Shemer T, Harpaz-Saad S, Cohen-Peer R, et al. (2011) Dual N- and C-terminal processing of citrus chlorophyllase precursor within the plastid membranes leads to the mature enzyme. Plant Cell Physiol 52:70-83.

Bak S, Beisson F, Bishop G, et al. (2011) Cytochromes P450. The Arabidopsis Book 9:e0144

Banala S, Moser S, Müller T, et al. (2010) Hypermodified fluorescent chlorophyll catabolites: source of blue luminescence in senescent leaves. Angew Chem Int Ed 49:5174-5177.

Barrett J, Jeffrey SW (1964) Chlorophyllase and formation of an atypical chlorophyllide in marine algae. Plant Physiol 39:44-47.

Barry CS, McQuinn RP, Chung MY, et al. (2008) Amino acid substitutions in homologs of the STAY-GREEN protein are responsible for the green-flesh and chlorophyll retainer mutations of tomato and pepper. Plant Physiol Biochem 147:179-187.

Benedetti CE, Arruda P (2002) Altering the expression of the chlorophyllase gene ATHCOR1 in transgenic Arabidopsis caused changes in the chlorophyll-to-chlorophyllide ratio. Plant Physiol 128:1255-1263.

Berghold J, Breuker K, Oberhuber M, et al. (2002) Chlorophyll breakdown in spinach: on the structure of five nonfluorescent chlorophyll catabolites. Photosynth Res 74:109-119.

Berghold J, Eichmüller C, Hörtensteiner S, Kräutler B (2004) Chlorophyll breakdown in tobacco: on the structure of two nonfluorescent chlorophyll catabolites. Chem Biodivers 1:657-668.

Berghold J, Müller T, Ulrich M, et al. (2006) Chlorophyll breakdown in maize: on the structure of two nonfluorescent chlorophyll catabolites. Monatsh Chem 137:751-763.

Brandis A, Vainstein A, Goldschmidt EE (1996) Distribution of chlorophyllase among components of chloroplast membranes in Citrus sinensis organs. Plant Physiol Biochem 34:49-54.

Briscoe AD, Chittka L (2001) The evolution of color vision in insects. Annu Rev Entomol 46:471-510.

Büchert AM, Civello PM, Martínez GA (2011) Characterization of Mg-dechelating substance in senescent and pre-senescent Arabidopsis thaliana leaves. Biol Plant 55:75-82.

Christ B, Schelbert S, Aubry S, et al. (2012) MES16, a member of the methylesterase protein family, specifically demethylates fluorescent chlorophyll catabolites during chlorophyll breakdown in Arabidopsis. Plant Physiol 158:628-641.

Christ B, Süssenbacher I, Moser S, et al. (2013) Cytochrome P450 CYP89A9 is involved in the formation of major chlorophyll catabolites during leaf senescence in Arabidopsis. Plant Cell 25:1868-1880.

Curty C, Engel N (1996) Detection, isolation and structure elucidation of a chlorophyll a catabolite from autumnal senescent leaves of Cercidiphyllum japonicum. Phytochemistry 42:1531-1536.

Dosnon-Olette R, Schröder P, Bartha B, et al. (2011) Enzymatic basis for fungicide removal by Elodea canadensis. Environ Sci Pollut Res 18:1015-1021. 
Downie A, Miyazaki S, Bohnert H, et al. (2004) Expression profiling of the response of Arabidopsis thaliana to methanol stimulation. Phytochemistry 65:2305-2316.

Fall R, Benson AA (1996) Leaf methanol — the simplest natural product from plants. Trends Plant Sci 1:296301.

Feller U, Anders I, Mae T (2008) Rubiscolytics: fate of Rubisco after its enzymatic function in a cell is terminated. J Exp Bot 59:1615-1624.

Ginsburg S, Matile P (1993) Identification of catabolites of chlorophyll porphyrin in senescent rape cotyledons. Plant Physiol 102:521-527.

Ginsburg S, Schellenberg M, Matile P (1994) Cleavage of chlorophyll-porphyrin. Requirement for reduced ferredoxin and oxygen. Plant Physiol 105:545-554.

Gout E, Aubert S, Bligny R, et al. (2000) Metabolism of methanol in plant cells. Carbon-13 nuclear magnetic resonance studies. Plant Physiol 123:287-296.

Gray J, Janick-Bruckner D, Bruckner B, et al. (2002) Light-dependent death of maize $l l s l$ cells is mediated by mature chloroplasts. Plant Physiol 130:1894-1907.

Greenberg JT, Ausubel FM (1993) Arabidopsis mutants compromised for the control of cellular damage during pathogenesis and aging. Plant J 4:327-341.

Harpaz-Saad S, Azoulay T, Arazi T, et al. (2007) Chlorophyllase is a rate-limiting enzyme in chlorophyll catabolism and is posttranslationally regulated. Plant Cell 19:1007-1022.

Hirashima M, Satoh S, Tanaka R, Tanaka A (2006) Pigment shuffling in antenna systems achieved by expressing prokaryotic chlorophyllide a oxygenase in Arabidopsis. J Biol Chem 281:15385-15393.

Hirashima M, Tanaka R, Tanaka A (2009) Light-independent cell death induced by accumulation of pheophorbide $a$ in Arabidopsis thaliana. Plant Cell Physiol 50:719-729.

Holden M (1961) The breakdown of chlorophyll by chlorophyllase. Biochem J 78:359-364.

Horie Y, Ito H, Kusaba M, et al. (2009) Participation of chlorophyll b reductase in the initial step of the degradation of light-harvesting chlorophyll $a / b$-protein complexes in Arabidopsis. J Biol Chem 284:17449-17456.

Hörtensteiner S (2009) Stay-green regulates chlorophyll and chlorophyll-binding protein degradation during senescence. Trends Plant Sci 14:155-162.

Hörtensteiner S (2006) Chlorophyll degradation during senescence. Annu Rev Plant Biol 57:55-77.

Hörtensteiner S (1998) NCC malonyltransferase catalyses the final step of chlorophyll breakdown in rape (Brassica napus). Phytochemistry 49:953-956.

Hörtensteiner S (2012) Update on the biochemistry of chlorophyll breakdown. Plant Mol Biol 1-13.

Hörtensteiner S, Feller U (2002) Nitrogen metabolism and remobilization during senescence. J Exp Bot 53:927937.

Hörtensteiner S, Kräutler B (2011) Chlorophyll breakdown in higher plants. Biochim Biophys Acta 1807:977988.

Hörtensteiner S, Rodoni S, Schellenberg M, et al. (2000) Evolution of chlorophyll degradation: the significance of RCC reductase. Plant Biol 2:63-67.

Hörtensteiner S, Vicentini F, Matile P (1995) Chlorophyll breakdown in senescent cotyledons of rape, Brassica napus L.: enzymatic cleavage of phaeophorbide $a$ in vitro. New Phytol 129:237-246. 
Hörtensteiner S, Wüthrich KL, Matile P, et al. (1998) The key step in chlorophyll breakdown in higher plants. Cleavage of pheophorbide $a$ macrocycle by a monooxygenase. J Biol Chem 273:15335-15339.

Igamberdiev AU, Bykova NV, Kleczkowski LA (1999) Origins and metabolism of formate in higher plants. Plant Physiol Biochem 37:503-513.

Ischebeck T, Zbierzak AM, Kanwischer M, Dörmann P (2006) A salvage pathway for phytol metabolism in Arabidopsis. J Biol Chem 281:2470-2477.

Iturraspe J, Moyano N, Frydman B (1995) A new 5-formylbilinone as the major chlorophyll a catabolite in tree senescent leaves. J Org Chem 60:6664-6665.

Jakob-Wilk D, Holland D, Goldschmidt EE, et al. (1999) Chlorophyll breakdown by chlorophyllase: isolation and functional expression of the Chlase 1 gene from ethylene-treated Citrus fruit and its regulation during development. Plant J 20:653-661.

Jiang H, Li M, Liang N, et al. (2007) Molecular cloning and function analysis of the stay green gene in rice. Plant J 52:197-209.

Jonker JW, Buitelaar M, Wagenaar E, et al. (2002) The breast cancer resistance protein protects against a major chlorophyll-derived dietary phototoxin and protoporphyria. Proc Natl Acad Sci U S A 99:15649-15654.

Kang J, Park J, Choi H, et al. (2011a) Plant ABC transporters. The Arabidopsis Book 9:e0153.

Kang K, Kim Y-S, Park S, Back K (2009) Senescence-induced serotonin biosynthesis and its role in delaying senescence in rice leaves. Plant Physiol 150:1380-1393.

Kang K, Park S, Natsagdorj U, et al. (2011b) Methanol is an endogenous elicitor molecule for the synthesis of tryptophan and tryptophan-derived secondary metabolites upon senescence of detached rice leaves. Plant J 66:247-257.

Kariola T, Brader G, Li J, Palva ET (2005) Chlorophyllase 1, a damage control enzyme, affects the balance between defense pathways in plants. Plant Cell 17:282-294.

Kleffmann T, Russenberger D, von Zychlinski A, et al. (2004) The Arabidopsis thaliana chloroplast proteome reveals pathway abundance and novel protein functions. Curr Biol 14:354-362.

Kräutler B, Banala S, Moser S, et al. (2010) A novel blue fluorescent chlorophyll catabolite accumulates in senescent leaves of the peace lily (Spathiphyllum wallisii) and indicates a divergent path of chlorophyll breakdown. FEBS Lett 584:4215-4221.

Kräutler B, Jaun B, Bortlik K-H, et al. (1991) On the enigma of chlorophyll degradation: the constitution of a secoporphinoid catabolite. Angew Chem Int Ed 30:1315-1318.

Kusaba M, Ito H, Morita R, et al. (2007) Rice NON-YELLOW COLORING1 is involved in light-harvesting complex II and grana degradation during leaf senescence. Plant Cell 19:1362-1375.

Li R, Moore M, Bonham-Smith PC, King J (2002) Overexpression of formate dehydrogenase in Arabidopsis thaliana resulted in plants tolerant to high concentrations of formate. J Plant Physiol 159:1069-1076.

Li R, Ziola B, King J (2000) Purification and characterization of formate dehydrogenase from Arabidopsis thaliana. J Plant Physiol 157:161-167.

Lippold F, Dorp K vom, Abraham M, et al. (2012) Fatty acid phytyl ester synthesis in chloroplasts of Arabidopsis. Plant Cell 24:2001-2014.

Losey FG, Engel N (2001) Isolation and characterization of a urobilinogenoidic chlorophyll catabolite from Hordeum vulgare L. J Biol Chem 276:27233-27236. 
Lu Y-P, Li Z-S, Drozdowicz Y-M, et al. (1998) AtMRP2, an Arabidopsis ATP binding cassette transporter able to transport glutathione S-conjugates and chlorophyll catabolites: functional comparisons with AtMRP1. Plant Cell 10:267-282.

Lundquist PK, Poliakov A, Bhuiyan NH, et al. (2012) The functional network of the Arabidopsis plastoglobule proteome based on quantitative proteomics and genome-wide coexpression analysis. Plant Physiol 158:1172-1192.

Luo Z, Zhang J, Li J, et al. (2013) A STAY-GREEN protein SISGR1 regulates lycopene and $\beta$-carotene accumulation by interacting directly with SIPSY1 during ripening processes in tomato. New Phytol 198(2):442-452.

Mach JM, Castillo AR, Hoogstraten R, Greenberg JT (2001) The Arabidopsis-accelerated cell death gene ACD2 encodes red chlorophyll catabolite reductase and suppresses the spread of disease symptoms. Proc Natl Acad Sci U S A 98:771-776.

Makino A, Osmond B (1991) Effect of nitrogen nutrition on nitrogen partitioning between chloroplasts and mitochondria in pea and wheat. Plant Physiol 96:355-362.

Matile P, Hörtensteiner S, Thomas H (1999) Chlorophyll degradation. Annu Rev Plant Physiol Plant Mol Biol 50:67-95.

Matile P, Hörtensteiner S, Thomas H, Kräutler B (1996) Chlorophyll breakdown in senescent leaves. Plant Physiol 112:1403-1409.

Matile P, Schellenberg M, Peisker C (1992) Production and release of a chlorophyll catabolite in isolated senescent chloroplasts. Planta 187:230-235.

Matile P, Schellenberg M, Vicentini F (1997) Localization of chlorophyllase in the chloroplast envelope. Planta 201:96-99.

Mayer H (1930) Untersuchungen über die Chlorophyllase. Planta 11:294-330.

Mecey C, Hauck P, Trapp M, et al. (2011) A critical role of STAYGREEN/Mendel's I locus in controlling disease symptom development during Pseudomonas syringae pv tomato infection of Arabidopsis. Plant Physiol 157:1965-1974.

Meguro M, Ito H, Takabayashi A, et al. (2011) Identification of the 7-hydroxymethyl chlorophyll a reductase of the chlorophyll cycle in Arabidopsis. Plant Cell 23:3442-3453.

Mendel G (1866) Versuche über Pflanzenhybriden. Verh Naturforsch Ver Brünn 4:3-47.

Mochizuki N, Brusslan JA, Larkin R, et al. (2001) Arabidopsis genomes uncoupled 5 (GUN5) mutant reveals the involvement of Mg-chelatase $\mathrm{H}$ subunit in plastid-to-nucleus signal transduction. Proc Natl Acad Sci U S A 98:2053-2058.

Morita R, Sato Y, Masuda Y, et al. (2009) Defect in non-yellow coloring 3, an $\alpha / \beta$ hydrolase-fold family protein, causes a stay-green phenotype during leaf senescence in rice. Plant J 59:940-952.

Moser S, Aarts M, Müller T, Kräutler B (2008a) A yellow chlorophyll catabolite is a pigment of the fall colours. Photochem Photobiol Sci 7:1577-1581.

Moser S, Müller T, Ebert MO, et al. (2008b) Blue luminescence of ripening bananas. Angew Chem Int Ed 47:8954-8957.

Moser S, Müller T, Holzinger A, et al. (2009) Fluorescent chlorophyll catabolites in bananas light up blue halos of cell death. Proc Natl Acad Sci U S A 106:15538-15543.

Mühlecker W, Kräutler B (1996) Breakdown of chlorophyll: constitution of nonfluorescing chlorophyllcatabolites from senescent cotyledons of the dicot rape. Plant Physiol Biochem 34:61-75. 
Mühlecker W, Kräutler B, Moser D, et al. (2000) Breakdown of chlorophyll: a fluorescent chlorophyll catabolite from sweet pepper (Capsicum annuum). Helv Chim Acta 83:278-286.

Mühlecker W, Ongania K-H, Kräutler B, et al. (1997) Tracking down chlorophyll breakdown in plants: elucidation of the constitution of a "fluorescent" chlorophyll catabolite. Angew Chem Int Ed 36:401404.

Müller T, Moser S, Ongania K-H, et al. (2006) A divergent path of chlorophyll breakdown in the model plant Arabidopsis thaliana. ChemBioChem 7:40-42.

Müller T, Rafelsberger M, Vergeiner C, Kräutler B (2011) A dioxobilane as product of a divergent path of chlorophyll breakdown in Norway maple. Angew Chem Int Ed 50:10724-10727.

Müller T, Ulrich M, Ongania KH, Kräutler B (2007) Colorless tetrapyrrolic chlorophyll catabolites found in ripening fruit are effective antioxidants. Angew Chem Int Ed 46:8699-8702.

Mur LAJ, Aubry S, Mondhe M, et al. (2010) Accumulation of chlorophyll catabolites photosensitizes the hypersensitive response elicited by Pseudomonas syringae in Arabidopsis. New Phytol 188:161-174.

Nakajima S, Ito H, Tanaka R, Tanaka A (2012) Chlorophyll $b$ reductase plays an essential role in maturation and storability of Arabidopsis seeds. Plant Physiol 160:261-273.

Obayashi T, Hayashi S, Saeki M, et al. (2009) ATTED-II provides coexpressed gene networks for Arabidopsis. Nucleic Acids Res 37:D987-D991.

Oberhuber M, Berghold J, Breuker K, et al. (2003) Breakdown of chlorophyll: a nonenzymatic reaction accounts for the formation of the colorless "nonfluorescent" chlorophyll catabolites. Proc Natl Acad Sci U S A 100:6910-6915.

Oberhuber M, Berghold J, Mühlecker W, et al. (2001) Chlorophyll breakdown - on a nonfluorescent chlorophyll catabolite from spinach. Helv Chim Acta 84:2615-2627.

Olson, Skavdahl, Ramberg, et al. (2000) Formate dehydrogenase in Arabidopsis thaliana: characterization and possible targeting to the chloroplast. Plant Sci 159:205-212.

Osmani SA, Bak S, Møller BL (2009) Substrate specificity of plant UDP-dependent glycosyltransferases predicted from crystal structures and homology modeling. Phytochemistry 70:325-347.

Paquette S, Møller BL, Bak S (2003) On the origin of family 1 plant glycosyltransferases. Phytochemistry 62:399-413.

Park S-Y, Yu J-W, Park J-S, et al. (2007) The senescence-induced STAYGREEN protein regulates chlorophyll degradation. Plant Cell 19:1649-1664.

Pattanayak GK, Venkataramani S, Hortensteiner S, et al. (2012) ACCELERATED CELL DEATH 2 suppresses mitochondrial oxidative bursts and modulates cell death in Arabidopsis. Plant J 69:589-600.

Pedras MSC, Zaharia IL, Gai Y, et al. (2001) In planta sequential hydroxylation and glycosylation of a fungal phytotoxin: avoiding cell death and overcoming the fungal invader. Proc Natl Acad Sci U S A 98:747752.

Peoples MB, Dalling MJ (1988) The interplay between proteolysis and amino acid metabolism during senescence and nitrogen allocation. In: Noodén LD, Leopold AC (eds) Senescence Aging Plants. Academic Press, San Diego, USA, pp 181-217

Pružinská A, Anders I, Aubry S, et al. (2007) In vivo participation of red chlorophyll catabolite reductase in chlorophyll breakdown. Plant Cell 19:369-387. 
Pružinská A, Anders I, Tanner G, et al. (2003) Chlorophyll breakdown: pheophorbide $a$ oxygenase is a Riesketype iron-sulfur protein, encoded by the accelerated cell death 1 gene. Proc Natl Acad Sci U S A 100:15259-15264.

Pružinská A, Tanner G, Aubry S, et al. (2005) Chlorophyll breakdown in senescent Arabidopsis leaves: characterization of chlorophyll catabolites and of chlorophyll catabolic enzymes involved in the degreening reaction. Plant Physiol 139:52-63.

Ren G, An K, Liao Y, et al. (2007) Identification of a novel chloroplast protein AtNYE1 regulating chlorophyll degradation during leaf senescence in Arabidopsis. Plant Physiol 144:1429-1441.

Ren GD, Zhou Q, Wu SX, et al. (2010) Reverse genetic identification of CRN1 and its distinctive role in chlorophyll degradation in Arabidopsis. J Integr Plant Biol 52:496-504.

Rodoni S, Mühlecker W, Anderl M, et al. (1997) Chlorophyll breakdown in senescent chloroplasts. Cleavage of pheophorbide $a$ in two enzymic steps. Plant Physiol 115:669-676.

Saga Y, Tamiaki H (2012) Demetalation of chlorophyll pigments. Chem Biodivers 9:1659-1683.

Sakuraba Y, Balazadeh S, Tanaka R, et al. (2012a) Overproduction of Chl $b$ retards senescence through transcriptional reprogramming in Arabidopsis. Plant Cell Physiol 53:505-517.

Sakuraba Y, Kim Y-S, Yoo S-C, et al. (2013) 7-Hydroxymethyl chlorophyll a reductase functions in metabolic channeling of chlorophyll breakdown intermediates during leaf senescence. Biochem Biophys Res Commun 430:32-37.

Sakuraba Y, Schelbert S, Park SY, et al. (2012b) STAY-GREEN and chlorophyll catabolic enzymes interact at light-harvesting complex II for chlorophyll detoxification during leaf senescence in Arabidopsis. Plant Cell 24:507-18.

Sakuraba Y, Yokono M, Akimoto S, et al. (2010) Deregulated chlorophyll $b$ synthesis reduces the energy transfer rate between photosynthetic pigments and induces photodamage in Arabidopsis thaliana. Plant Cell Physiol 51:1055-1065.

Sato Y, Moria R, Katsuma S, et al. (2009) Two short-chain dehydrogenase/reductases, NON-YELLOW COLORING 1 and NYC1-LIKE, are required for chlorophyll $b$ and light-harvesting complex II degradation during senescence in rice. Plant J 57:120-131.

Scheer H (2006) An overview of chlorophylls and bacteriochlorophylls: biochemistry, biophysics, functions and applications. In: Grimm B, Porra R, Rüdiger W, Scheer H (eds) Chlorophylls Bacteriochlorophylls. Biochemistry, Biophysics, Functions and Applications, Springer, Dordrecht, The Netherlands, pp 1-26

Schelbert S, Aubry S, Burla B, et al. (2009) Pheophytin pheophorbide hydrolase (pheophytinase) is involved in chlorophyll breakdown during leaf senescence in Arabidopsis. Plant Cell 21:767-785

Schellenberg M, Matile P, Thomas H (1990) Breakdown of chlorophyll in chloroplasts of senescent barley leaves depends on ATP. J Plant Physiol 136:564-568.

Schellenberg M, Matile P, Thomas H (1993) Production of a presumptive chlorophyll catabolite in vitro: requirement for reduced ferredoxin. Planta 191:417-420.

Schenk N, Schelbert S, Kanwischer M, et al. (2007) The chlorophyllases AtCLH1 and AtCLH2 are not essential for senescence-related chlorophyll breakdown in Arabidopsis thaliana. FEBS Lett 581:5517-5525.

Scherl M, Müller T, Kräutler B (2012) Chlorophyll catabolites in senescent leaves of the lime tree (Tilia cordata). Chem Biodivers 9:2605-2617.

Schuler MA, Duan H, Bilgin M, Ali S (2006) Arabidopsis cytochrome P450s through the looking glass: a window on plant biochemistry. Phytochem Rev 5:205-237. 
Shimoda Y, Ito H, Tanaka A (2012) Conversion of chlorophyll $b$ to chlorophyll $a$ precedes magnesium dechelation for protection against necrosis in Arabidopsis. Plant J 72:501-511.

Shioi Y, Tomita N, Tsuchiya T, Takamiya K (1996a) Conversion of chlorophyllide to pheophorbide by Mgdechelating substance in extracts of Chenopodium album. Plant Physiol Biochem 34:41-47.

Shioi Y, Watanabe K, Takamiya K (1996b) Enzymatic conversion of pheophorbide $a$ to a precursor of pyropheophorbide $a$ in leaves of Chenopodium album. Plant Cell Physiol 37:1143-1149.

Spassieva S, Hille J (2002) A lesion mimic phenotype in tomato obtained by isolating and silencing an Lls I homologue. Plant Sci 162:543-549.

Sugishima M, Kitamori Y, Noguchi M, et al. (2009) Crystal structure of red chlorophyll catabolite reductase: enlargement of the ferredoxin-dependent bilin reductase family. J Mol Biol 389:376-387.

Sugishima M, Okamoto Y, Noguchi M, et al. (2010) Crystal structures of the substrate-bound forms of red chlorophyll catabolite reductase: implications for site-specific and stereospecific reaction. J Mol Biol 402:879-891.

Suzuki T, Shioi Y (2002) Re-examination of Mg-dechelation reaction in the degradation of chlorophylls using chlorophyllin $a$ as substrate. Photosynth Res 74:217-223.

Suzuki Y, Amano T, Shioi Y (2006) Characterization and cloning of the chlorophyll-degrading enzyme pheophorbidase from cotyledons of radish. Plant Physiol 140:716-725.

Suzuki Y, Doi M, Shioi Y (2002) Two enzymatic reaction pathways in the formation of pyropheophorbide $a$. Photosynth Res 74:225-233.

Suzuki Y, Shioi Y (1999) Detection of chlorophyll breakdown products in the senescent leaves of higher plants. Plant Cell Physiol 40:909-915.

Suzuki Y, Tanabe K, Shioi Y (1999) Determination of chemical oxidation products of chlorophyll and porphyrin by high-performance liquid chromatography. J Chromatogr A. 839:85-91.

Tanaka R, Hirashima M, Satoh S, Tanaka A (2003) The Arabidopsis-accelerated cell death gene ACD1 is involved in oxygenation of pheophorbide $a$ : inhibition of pheophorbide $a$ oxygenase activity does not lead to the "stay-green" phenotype in Arabidopsis. Plant Cell Physiol 44:1266-1274.

Tanaka R, Tanaka A (2011) Chlorophyll cycle regulates the construction and destruction of the light-harvesting complexes. Biochim Biophys Acta 1807:968-976.

Tang Y, Li M, Chen Y, et al. (2011) Knockdown of OsPAO and OsRCCR1 cause different plant death phenotypes in rice. J Plant Physiol 168:1952-1959.

Thomas H, Howarth CJ (2000) Five ways to stay green. J Exp Bot 51:329-337.

Tommasini R, Vogt E, Fromenteau M, et al. (1998) An ABC transporter of Arabidopsis thaliana has both glutathione-conjugate and chlorophyll catabolite transport activity. Plant J 13:773-780.

Tsuchiya T, Ohta H, Okawa K, et al. (1999) Cloning of chlorophyllase, the key enzyme in chlorophyll degradation: finding of a lipase motif and the induction by methyl jasmonate. Proc Natl Acad Sci U S A 96:15362-15367.

Valentin HE, Lincoln K, Moshiri F, et al. (2006) The Arabidopsis vitamin E pathway gene5-1 mutant reveals a critical role for phytol kinase in seed tocopherol biosynthesis. Plant Cell 18:212-224.

Vergeiner C, Banala S, Kräutler B (2013) Chlorophyll breakdown in senescent banana leaves: catabolism reprogrammed for biosynthesis of persistent blue fluorescent tetrapyrroles. Chem Eur J. doi: 10.1002/chem.201301907 
Vicentini F, Iten F, Matile P (1995) Development of an assay for Mg-dechelatase of oilseed rape cotyledons, using chlorophyllin as the substrate. Physiol Plant 94:57-63.

Wagner D, Przybyla D, op den Camp R, et al. (2004) The genetic basis of singlet oxygen-induced stress responses of Arabidopsis thaliana. Science 306:1183-1185.

Willstätter R, Stoll A (1911) Examinations on chloropyll, XI Chlorophyllase. Justus Liebigs Ann Chem 378:1872.

Wüthrich KL, Bovet L, Hunziker PE, et al. (2000) Molecular cloning, functional expression and characterisation of RCC reductase involved in chlorophyll catabolism. Plant J 21:189-198.

Yao N, Greenberg JT (2006) Arabidopsis ACCELERATED CELL DEATH2 modulates programmed cell death. Plant Cell 18:397-411.

Zhang K, Gan S-S (2012) An abscisic acid-AtNAP transcription factor-SAG113 protein phosphatase 2C regulatory chain for controlling dehydration in senescing Arabidopsis leaves. Plant Physiol 158:961969.

Zhou C, Han L, Pislariu C, et al. (2011) From model to crop: functional analysis of a STAY-GREEN gene in the model legume Medicago truncatula and effective use of the gene for Alfalfa improvement. Plant Physiol 157:1483-1496. 
894 Figure 1. Chl breakdown by the PAO pathway. Enzymes and their target sites (dashed circles) are indicated.

895 Magnesium, phytol, formate and methanol, the major by-products of the PAO pathway, are also depicted. Side 896 chain residues $\left(\mathrm{R}^{1}-\mathrm{R}^{4}\right)$ of the to date characterized NCCs, DNCCs and FCCs are listed in Table 1. Inset: Chl breakdown leads to the formation of water soluble non-phototoxic catabolites. Relevant pyrrole rings and carbon

898 atoms are labelled in the structure of $\mathrm{Chl} a$. For abbreviations, see text.

899

900 Figure 2. Topology of Chl breakdown. Proteins involved in the degradation of phototoxic intermediates in the 901 chloroplast are depicted in red, translocation mechanisms across the chloroplast envelope and the tonoplast in 902 blue and enzymes that modify FCC side chains in brown. See text for more information and abbreviations.

903

904 Figure 3. UV/Vis spectra of FCCs, NCCs, DNCCs and YCCs. The YCC spectrum is adapted from Moser et al. 905 (2008a).

906

907 Figure 4. Schematic representation of the loss of absorption capacity of different Chl catabolites during Chl 908 breakdown. The enzymes having a direct influence on the UV/Vis spectra of the Chl catabolites are shown. The $909 \mathrm{UV} / \mathrm{Vis}$ spectra are schematically drawn. Note that relative absorptions cannot be compared between different catabolites. 
Table 1. List of FCCs, NCCs and DNCCs identified from higher plants

\begin{tabular}{|c|c|c|c|c|c|c|c|}
\hline Name & $\mathbf{R}^{1 \mathbf{c}}$ & $\mathbf{R}^{2 \mathrm{c}}$ & $\mathbf{R}^{3 \mathbf{c}}$ & $\mathbf{R}^{4 \mathbf{c}}$ & $\begin{array}{l}\text { C1- } \\
\text { epimer }^{d}\end{array}$ & Source $^{\mathrm{e}}$ & Reference \\
\hline \multicolumn{8}{|l|}{$p \mathrm{FCCs}$} \\
\hline$p \mathrm{FCC}$ & $\mathrm{H}$ & $\mathrm{CH}_{3}$ & Vinyl & $\mathrm{H}$ & 1 & $\mathrm{E}$ & (Mühlecker et al. 1997) \\
\hline epi-pFCC & $\mathrm{H}$ & $\mathrm{CH}_{3}$ & Vinyl & $\mathrm{H}$ & epi & $\mathrm{E}$ & (Mühlecker et al. 2000) \\
\hline \multicolumn{8}{|l|}{$m \mathrm{FCCs}$} \\
\hline$A t-\mathrm{FCC}-1^{\mathrm{a}}$ & $\mathrm{OH}$ & $\mathrm{H}$ & Vinyl & $\mathrm{H}$ & 1 & $\mathrm{~L}$ & (Pružinská et al. 2005) \\
\hline$A t-\mathrm{FCC}-2^{\mathrm{a}}$ & $\mathrm{H}$ & $\mathrm{H}$ & Vinyl & $\mathrm{H}$ & 1 & $\mathrm{~L}$ & (Pružinská et al. 2005) \\
\hline \multicolumn{8}{|l|}{$h m$ FCCs } \\
\hline$M c-$ FCC $-49^{\mathrm{b}}$ & $O$-glucosyl & $\mathrm{CH}_{3}$ & Vinyl & Daucic acid & epi & $\mathrm{F}$ & (Moser et al. 2009) \\
\hline$M c-$ FCC- $56^{\mathrm{b}}$ & $\mathrm{OH}$ & $\mathrm{CH}_{3}$ & Vinyl & Daucic acid & epi & $\mathrm{F}$ & (Moser et al. 2008b) \\
\hline$M a-F C C-61^{\mathrm{b}}$ & $\mathrm{OH}$ & $\mathrm{CH}_{3}$ & Vinyl & Digalactosylglyceryl & epi & $\mathrm{L}$ & (Banala et al. 2010) \\
\hline$M a-F C C-63 / 64^{b}$ & $\mathrm{OH}$ & $\mathrm{CH}_{3}$ & Vinyl & Glucopyranosyl & epi & $\mathrm{L}$ & (Vergeiner et al. 2013) \\
\hline$M a-$ FCC $-69^{\mathrm{b}}$ & $\mathrm{OH}$ & $\mathrm{CH}_{3}$ & Vinyl & $\begin{array}{l}\text { 3,4-dihydroxyphenyl- } \\
\text { ethyl-glucopyranosyl }\end{array}$ & epi & $\mathrm{L}$ & (Vergeiner et al. 2013) \\
\hline$S w-$ FCC$-62^{\mathrm{b}}$ & $\mathrm{OH}$ & $\mathrm{CH}_{3}$ & Vinyl & $\begin{array}{l}\text { Dihydroxyphenyl- } \\
\text { ethylglucosyl }\end{array}$ & 1 & $\mathrm{~L}$ & (Kräutler et al. 2010) \\
\hline \multicolumn{8}{|c|}{ ent } \\
\hline$A t-\mathrm{NCC}-1^{\mathrm{a}}$ & $O$-glucosyl & $\mathrm{H}$ & Vinyl & $\mathrm{H}$ & 1 & $\mathrm{~L}$ & (Pružinská et al. 2005) \\
\hline$A t-\mathrm{NCC}-2^{\mathrm{a}}$ & $\mathrm{OH}$ & $\mathrm{H}$ & Vinyl & $\mathrm{H}$ & 1 & $\mathrm{~L}$ & (Pružinská et al. 2005) \\
\hline$A t-\mathrm{NCC}-3^{\mathrm{a}}$ & $\mathrm{OH}^{\mathrm{f}}$ & $\mathrm{H}$ & Vinyl & $\mathrm{H}$ & 1 & $\mathrm{~L}$ & (Pružinská et al. 2005) \\
\hline$A t-\mathrm{NCC}-4^{\mathrm{a}}$ & $O$-glucosyl & $\mathrm{CH}_{3}$ & Vinyl & $\mathrm{H}$ & 1 & $\bar{L}$ & (Pružinská et al. 2005) \\
\hline$A t-\mathrm{NCC}-5^{\mathrm{a}}$ & $\mathrm{H}$ & $\mathrm{H}$ & Vinyl & $\mathrm{H}$ & 1 & $\mathrm{~L}$ & (Pružinská et al. 2005) \\
\hline$B n-\mathrm{NCC}-1^{\mathrm{a}}$ & $O$-malonyl & $\mathrm{H}$ & Vinyl & $\mathrm{H}$ & 1 & $\mathrm{~L}$ & (Mühlecker and Kräutler 1996) \\
\hline$B n-\mathrm{NCC}-2^{\mathrm{a}}$ & $O$-glucosyl & $\mathrm{H}$ & Vinyl & $\mathrm{H}$ & 1 & $\mathrm{~L}$ & (Mühlecker and Kräutler 1996) \\
\hline$B n-\mathrm{NCC}-3^{\mathrm{a}}$ & $\mathrm{OH}$ & $\mathrm{H}$ & Vinyl & $\mathrm{H}$ & 1 & $\mathrm{~L}$ & (Mühlecker and Kräutler 1996) \\
\hline$B n-\mathrm{NCC}-4^{\mathrm{a}}$ & $\mathrm{H}$ & $\mathrm{H}$ & Vinyl & $\mathrm{H}$ & 1 & $\mathrm{~L}$ & (Pružinská et al. 2005) \\
\hline$C j-\mathrm{NCC}-1^{\mathrm{a}}$ & $\mathrm{OH}$ & $\mathrm{CH}_{3}$ & Vinyl & $\mathrm{H}$ & epi & $\mathrm{L}$ & (Curty and Engel 1996) \\
\hline$C j-\mathrm{NCC}^{2} 2^{\mathrm{a}}$ & $\mathrm{H}$ & $\mathrm{CH}_{3}$ & Vinyl & $\mathrm{H}$ & epi & $\mathrm{L}$ & (Oberhuber et al. 2003) \\
\hline$H v-\mathrm{NCC}-1^{\mathrm{a}}$ & $\mathrm{OH}$ & $\mathrm{CH}_{3}$ & Dihydroxyethyl & $\mathrm{H}$ & 1 & $\mathrm{~L}$ & (Kräutler et al. 1991) \\
\hline$L o-\mathrm{NCC}-1^{\mathrm{a}}$ & $\mathrm{OH}$ & $\mathrm{CH}_{3}$ & Vinyl & $\mathrm{H}$ & nd & $\mathrm{L}$ & (Iturraspe et al. 1995) \\
\hline$L s-\mathrm{NCC}-1^{\mathrm{a}}$ & $\mathrm{OH}$ & $\mathrm{CH}_{3}$ & Vinyl & $\mathrm{H}$ & nd & $\mathrm{L}$ & (Iturraspe et al. 1995) \\
\hline$M s-\mathrm{NCC}-2^{\mathrm{a}}$ & $\mathrm{OH}$ & $\mathrm{CH}_{3}$ & Vinyl & $\mathrm{H}$ & epi & $\mathrm{F}$ & (Müller et al. 2007) \\
\hline$N r$-NCC-1 ${ }^{\mathrm{a}}$ & $O$-glucosylmalonyl & $\mathrm{CH}_{3}$ & Vinyl & $\mathrm{H}$ & epi & $\mathrm{L}$ & (Berghold et al. 2004) \\
\hline$N r$-NCC- $2^{\mathrm{a}}$ & $O$-glucosyl & $\mathrm{CH}_{3}$ & Vinyl & $\mathrm{H}$ & epi & $\mathrm{L}$ & (Berghold et al. 2004) \\
\hline$P c-\mathrm{NCC}-1^{\mathrm{a}}$ & $O$-glucosyl & $\mathrm{CH}_{3}$ & Vinyl & $\mathrm{H}$ & epi & $\mathrm{F}$ & (Müller et al. 2007) \\
\hline$P c-\mathrm{NCC}-2^{\mathrm{a}}$ & $\mathrm{OH}$ & $\mathrm{CH}_{3}$ & Vinyl & $\mathrm{H}$ & epi & $\mathrm{F}$ & (Müller et al. 2007) \\
\hline So-NCC- $1^{\mathrm{a}}$ & $\mathrm{OH}$ & $\mathrm{H}$ & Dihydroxyethyl & $\mathrm{H}$ & epi & $\mathrm{L}$ & (Berghold et al. 2002) \\
\hline So-NCC- $2^{\mathrm{a}}$ & $\mathrm{OH}$ & $\mathrm{CH}_{3}$ & Dihydroxyethyl & $\mathrm{H}$ & epi & $\mathrm{L}$ & (Oberhuber et al. 2001) \\
\hline So-NCC- $3^{\mathrm{a}}$ & $\mathrm{OH}$ & $\mathrm{H}$ & Vinyl & $\mathrm{H}$ & epi & $\mathrm{L}$ & (Berghold et al. 2002) \\
\hline So-NCC-4 ${ }^{\mathrm{a}}$ & $\mathrm{OH}$ & $\mathrm{CH}_{3}$ & Vinyl & $\mathrm{H}$ & epi & $\mathrm{L}$ & (Berghold et al. 2002) \\
\hline So-NCC- $5^{\mathrm{a}}$ & $\mathrm{H}$ & $\mathrm{CH}_{3}$ & Vinyl & $\mathrm{H}$ & epi & $\mathrm{L}$ & (Berghold et al. 2002) \\
\hline$S w-N C C-58^{b}$ & $\mathrm{OH}$ & $\mathrm{CH}_{3}$ & Vinyl & $\mathrm{H}$ & 1 & $\mathrm{~L}$ & (Kräutler et al. 2010) \\
\hline$T c-\mathrm{NCC}-1$ & $O$-glucosyl & $\mathrm{CH}_{3}$ & Dihydroxyethyl & $\mathrm{H}$ & epi & $\mathrm{L}$ & (Scherl et al. 2012) \\
\hline$T c-\mathrm{NCC}-2$ & $O$-glucosyl & $\mathrm{CH}_{3}$ & Vinyl & $\mathrm{H}$ & epi & $\mathrm{L}$ & (Scherl et al. 2012) \\
\hline $\mathrm{Zm}-\mathrm{NCC}-1^{\mathrm{a}}$ & $O$-glucosyl & $\mathrm{CH}_{3}$ & Dihydroxyethyl & $\mathrm{H}$ & epi & $\mathrm{L}$ & (Berghold et al. 2006) \\
\hline $\mathrm{Zm}-\mathrm{NCC}-2^{\mathrm{a}}$ & $O$-glucosyl & $\mathrm{CH}_{3}$ & Vinyl & $\mathrm{H}$ & epi & $\mathrm{L}$ & (Berghold et al. 2006) \\
\hline \multicolumn{8}{|l|}{ DNCCs } \\
\hline$H v$-UCC-1 $1^{\mathrm{a}, \mathrm{g}, \mathrm{h}}$ & $\mathrm{OH}$ & $\mathrm{CH}_{3}$ & Dihydroxyethyl & $\mathrm{H}$ & 1 & $\mathrm{~L}$ & (Losey and Engel 2001) \\
\hline$A p-\mathrm{UCC}-1^{\mathrm{a}, \mathrm{g}, \mathrm{h}}$ & $\mathrm{OH}$ & $\mathrm{CH}_{3}$ & Dihydroxyethyl & $\mathrm{H}$ & epi & $\mathrm{L}$ & (Müller et al. 2011) \\
\hline$A t-\mathrm{NDCC}-1$ & $\mathrm{OH}$ & $\mathrm{H}$ & Vinyl & $\mathrm{H}$ & epi & $\mathrm{L}$ & (Christ et al. 2013) \\
\hline \multicolumn{8}{|l|}{ YCCs } \\
\hline$C j$-YCC-1 & $\mathrm{OH}$ & $\mathrm{CH}_{3}$ & Vinyl & $\mathrm{H}$ & $N / A$ & $\mathrm{~L}$ & (Moser et al. 2008a) \\
\hline$T c-Y C C-1$ & $O$-glucosyl & $\mathrm{CH}_{3}$ & Dihydroxyethyl & $\mathrm{H}$ & $N / A$ & $\mathrm{~L}$ & (Scherl et al. 2012) \\
\hline
\end{tabular}

${ }^{a}$ A nomenclature for NCCs (and FCCs) has been defined (Ginsburg and Matile 1993) in which a prefix indicates the plant species and a suffix number indicates decreasing polarity in reversed-phase HPLC

${ }^{\mathrm{b}}$ These catabolites are indexed according to their retention time in HPLC analysis. Ap Acer platanoides, At Arabidopsis thaliana, Bn Brassica napus, Cj Cercidiphyllum japonicum, Hv Hordeum vulgare, Lo Liquidambar orientalis, Ls Liquidambar styraciflua, Ma Muca acuminate, Mc Musa cavendish, Ms Malus sylvestris, Nr Nicotiana rustica, Pc Pyrus communis, So Spinacia oleracea, Sw Spathiphyllum wallisii, Tc Tilia cordata, Zm Zea mays

${ }^{\mathrm{c}} \mathrm{R}^{1}-\mathrm{R}^{4}$ indicate residues at $\mathrm{C}^{3}, \mathrm{C}^{2}, \mathrm{C} 13^{2}$ and $\mathrm{C} 17^{3}$ side positions, respectively, of FCCs, NCCs, DNCCs and YCCs as shown in Figure 1

${ }^{\mathrm{d}} \mathrm{C} 1$ stereochemistry refers to the type of $p \mathrm{FCC}$, i.e. $p \mathrm{FCC}(1)$ or epi-pFCC (epi), formed in the respective species or genus; nd, not determined; N/A, not applicable

e Source of material used for catabolite isolation: $\mathrm{E}$, in vitro enzymatic PAO/RCCR assays; F, fruits; L, leaves

${ }^{\mathrm{f}}$ In $A t$-NCC-3, the site of hydroxylation is indicated to be $\mathrm{C} 7$ (rather than $\mathrm{C}^{2}$ ) (Müller et al. 2006)

${ }^{\mathrm{g}} \mathrm{Hv}$-UCC-1 and Ap-UCC-1 are indicated to be pseudo-enantiomers (Müller et al. 2011)

${ }^{\mathrm{h}}$ DNCCs have earlier been named urobilinogenoidic Chl catabolites (UCCs) 


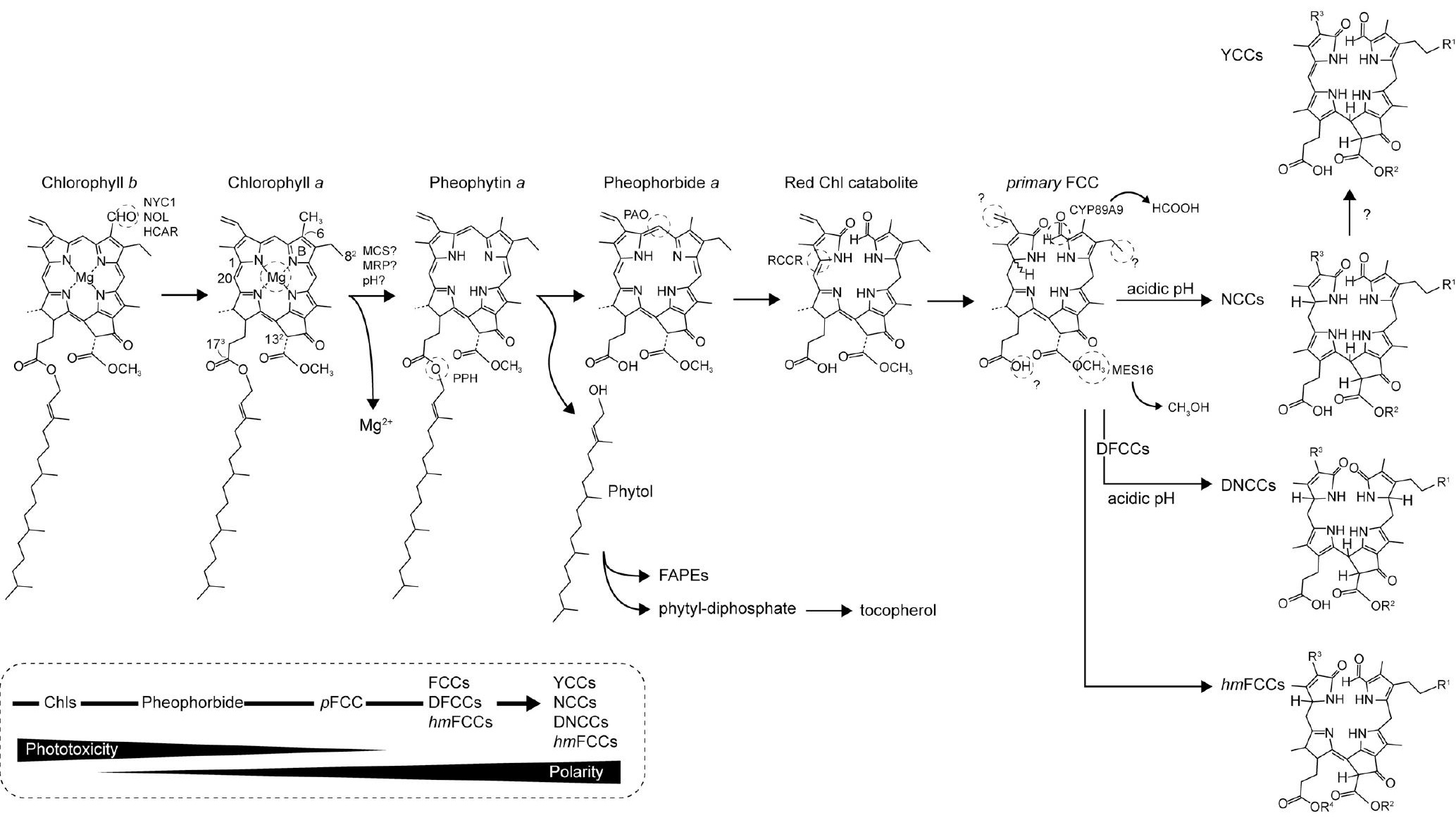




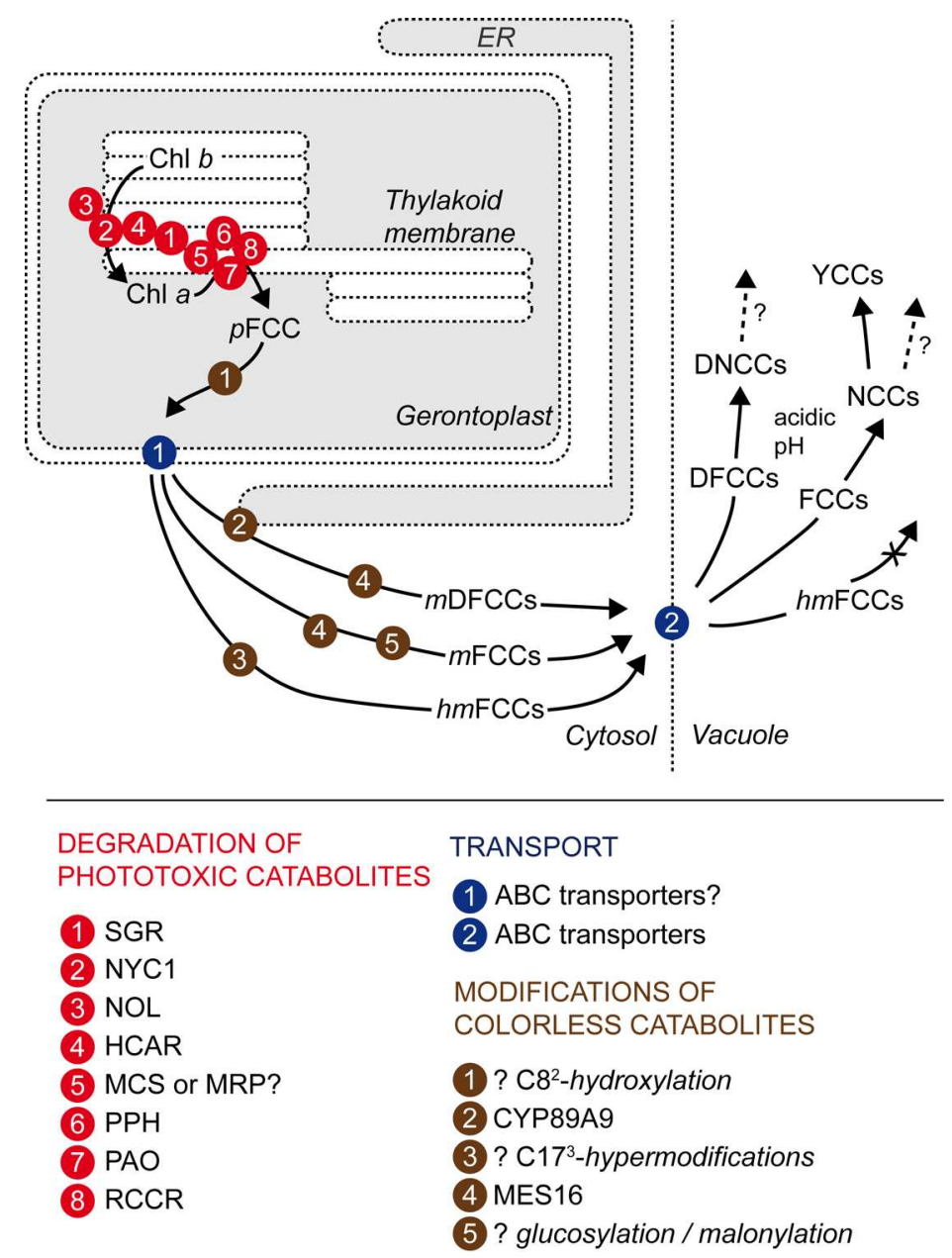



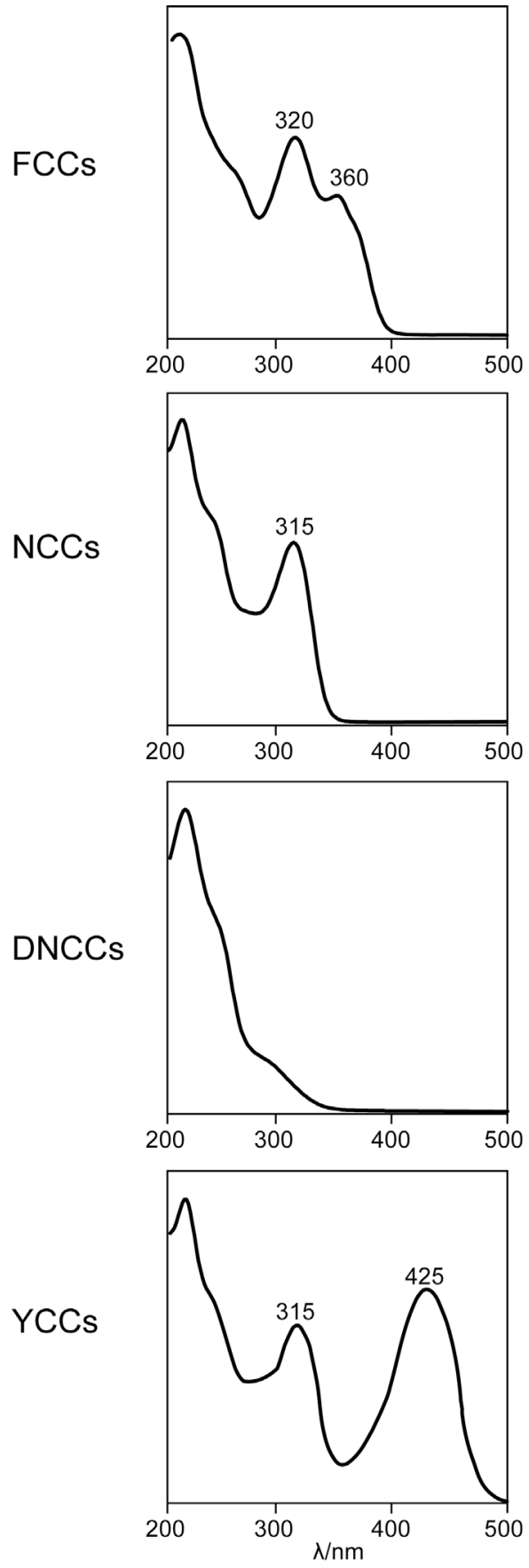


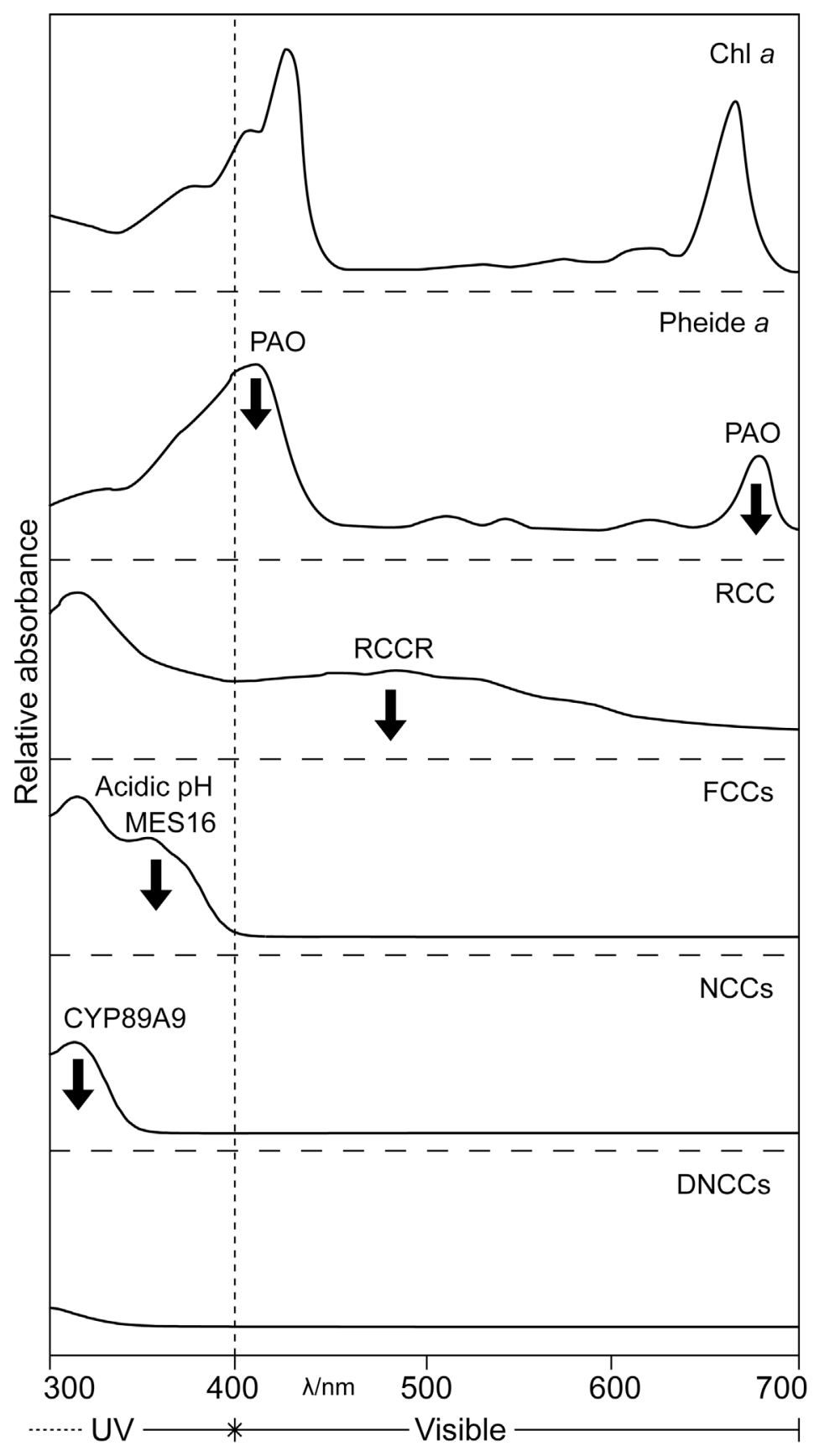

